\title{
Improved Performance of an Air Cooled Condenser (ACC) Using SPX Wind Guide Technology at Coal-Based Thermoelectric Power Plants [DEFC2606NT06549]
}

\author{
Final Scientific/Technical Report
}

Reporting Period: 10/1/08 - 12/31/10

Principal Author: Ken Mortensen

SPX Cooling Technologies, Inc.

7401 West $129^{\text {th }}$ Street

Overland Park, KS 66213

Phone: 913-664-7723

Fax: 913-664-7871

E-mail: ken.mortensen@spx.com

DATE: $3 / 31 / 11$

This report is for the completed project. 


\title{
DISCLAIMER
}

"This report was prepared as an account of work sponsored by an agency of the United States Government. Neither the United States Government nor any agency thereof, nor any of their employees, makes any warranty, express or implied, or assumes any legal liability or responsibility for the accuracy, completeness, or usefulness of any information, apparatus, product, or process disclosed, or represents that its use would not infringe privately owned rights. Reference herein to any specific commercial product, process, or service by trade name, trademark, manufacturer, or otherwise does not necessarily constitute or imply its endorsement, recommendation, or favoring by the United States Government or any agency thereof. The views and opinions of authors expressed herein do not necessarily state or reflect those of the United States Government or any agency thereof."

\begin{abstract}
:
This project added a new airflow enhancement technology to an existing ACC cooling process at a selected coal power plant. Airflow parameters and efficiency improvement for the main plant cooling process using the applied technology were determined and compared with the capabilities of existing systems.
\end{abstract}

The project required significant planning and pre-test execution in order to reach the required Air Cooled Condenser system configuration for evaluation. A host Power Plant ACC system had to be identified, agreement finalized, and addition of the SPX ACC Wind Guide Technology completed on that site. Design of the modification, along with procurement, fabrication, instrumentation, and installation of the new airflow enhancement technology were executed. Baseline and post-modification cooling system data was collected and evaluated. The improvement of ACC thermal performance after SPX wind guide installation was clear. Testing of the improvement indicates there is a $5 \%$ improvement in heat transfer coefficient in high wind conditions and $1 \%$ improvement at low wind speed. The benefit increased with increasing wind speed.

This project was completed on schedule and within budget. 


\section{Table of Contents}

- Project Description

- Results

- Conclusions

- References

36

- Appendix 


\section{Project Description}

\section{Project Objectives}

The water savings potential of Dry Cooling technology, when one compares application to evaporative cooling processes, is enormous. The drawbacks have always included efficiency variation, efficiency reduction of power plants, and capital and operating costs of the ACC units. Cooling water savings for the total U.S. could be 7.8 Billion Gallons/Day, if all power and industrial towers were outfitted with this Dry Cooling technology. By this standard the savings would be 940 Million Gallons/Day in California alone, enough water for 13 Million residents domestic usage. [Domestic usage is inside the house, 71 GPD/person, source: AWWA]. This magnitude of water savings would allow relief from drought conditions or additional growth in many water-starved portions of the continental United States.

This project is aimed at reducing the efficiency variation of ACC cooling in high wind conditions, defined as 10-30 mph at the power plant site. SPX Cooling has developed a physical enhancement to the base ACC unit to improve airflow in windy conditions.

A pilot-scale test was required to verify improvement with such a design. This project added the new technology to an existing ACC cooling system at a selected coal power plant. Airflow parameters and efficiency improvement for the main plant cooling process using the applied technology were determined and compared with the capabilities of the existing system.

\section{Scientific and Technical Merit}

\section{Significance and background information}

The production of electricity requires a reliable, abundant, and predictable source of freshwater-a resource that is limited in many parts of the United States and throughout the world. The process of thermoelectric generation from fossil fuels such as coal, oil, and natural gas is water intensive. According to the U.S. Geological Survey in year 2000, thermoelectric-power withdrawals accounted for 48 percent of total water use, 39 percent of total freshwater withdrawals (136 billion gallons per day) for all categories, and 52 percent of fresh surface-water withdrawals ${ }^{[1]}$. See figure 1. 
Public Supply, 11 percent

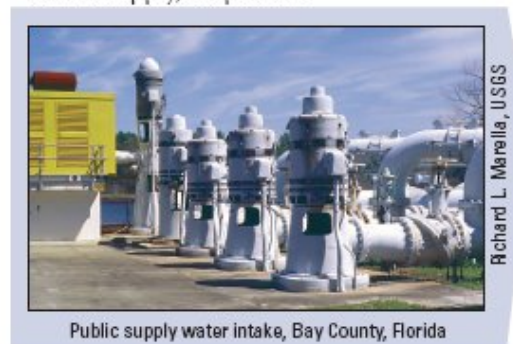

Public supply water intake, Bay County, Forida

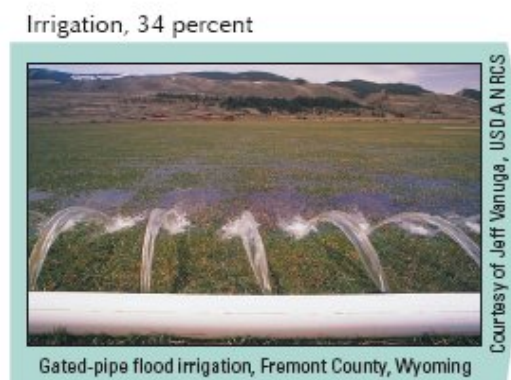

Aquaculture, less than 1 percent

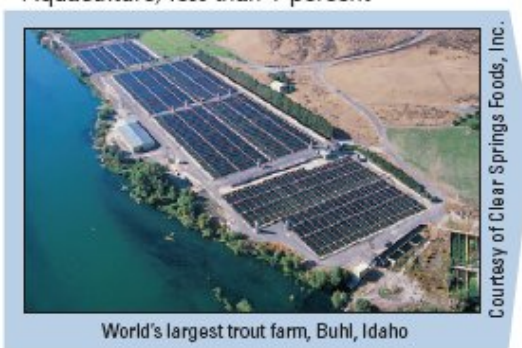

World's largest trout farm, Buhl, Idaho

Mining, less than 1 percent

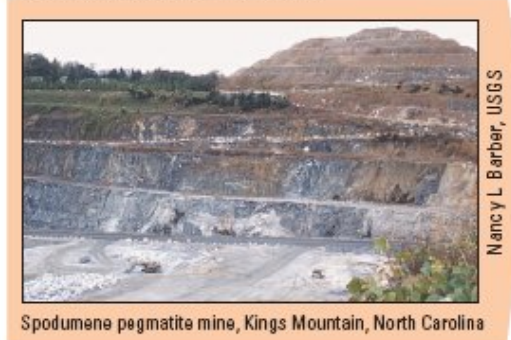

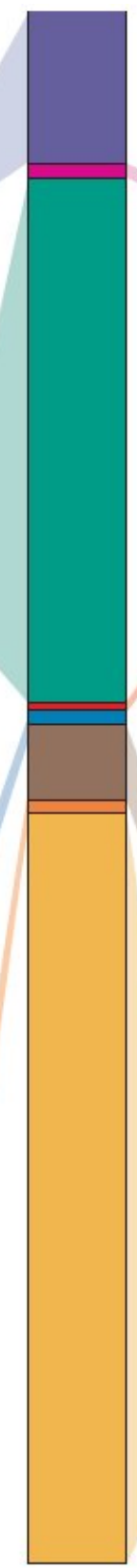

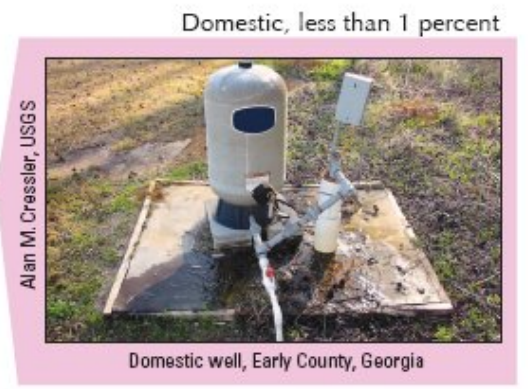

Livestock, less than 1 percent

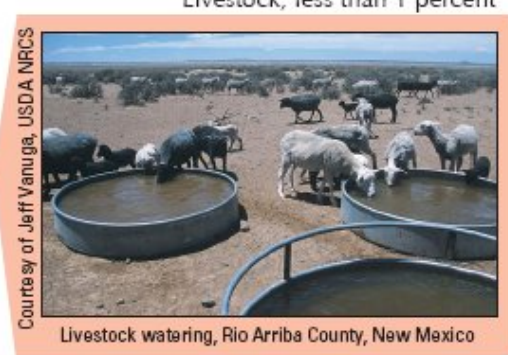

Industrial, 5 percent

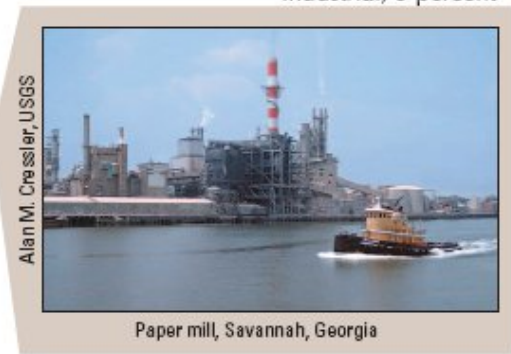

Thermoelectric Power, 48 percent

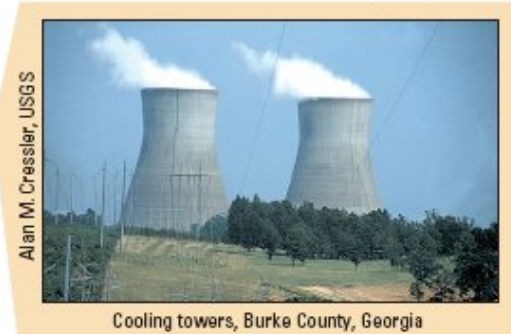

Cooling towers, Burke County, Georgia

Figure 1: Category of water withdrawals for year 2000

In all fairness, one should not discuss the withdrawal of freshwater by thermoelectric plants without discussing consumption. As illustrated in Figure 2, the 1995 consumption (through evaporation) was approximately 3 billion gallons each day ${ }^{[2]}$. 

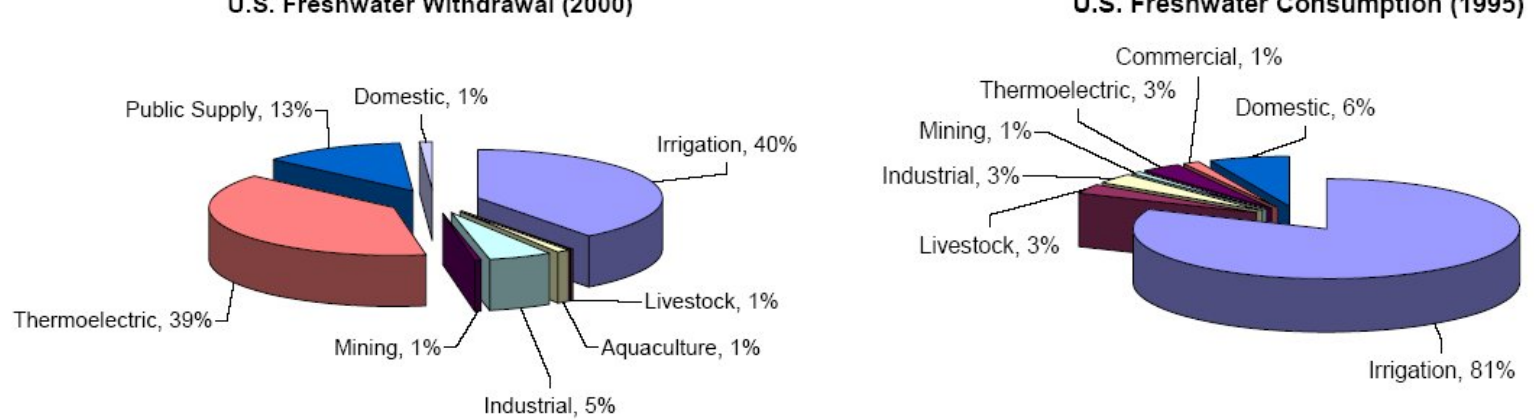

Figure 2: Comparison of domestic freshwater withdrawals and consumption

As a growing economy drives the need for more electricity, demands on freshwater supplies for thermoelectric power generation will also grow. However, electric utilities will have to compete with demands from other off-stream-use sectors such as public supply, domestic, commercial, agricultural, industrial, and mining. In addition, the need to leave water in streams and rivers to achieve environmental, ecological, and recreational goals will further complicate the future allocation of the nation's freshwater resources. As such, the availability of adequate supplies of freshwater to produce electricity and the potential impact of power plant operations on freshwater quality are receiving increased attention ${ }^{[3]}$.

\section{Water use in thermoelectric power plants}

The generation of electricity from steam requires that the process steam be condensed at the aft end of a turbine. This is achieved most frequently through the use of cooling water. The process is greatly simplified in the Figure 3 illustration, although it is more typically a fossil fuel turbine exhaust, oil, gas, coal or nuclear power. The heat energy flows through a steam generator (boiler) where water is converted to steam and forced to build up pressures up to 3000-psi. This highpressure steam is channeled through a turbine which rotates at 3600 -rpm. The turbine drives an electric generator, which feeds power to the grid. Critical to the operating efficiency of a power plant, is the pressure differential between steam turbine inlet and outlet. Steam, as it condenses, reduces its' volume 1700 times. This compaction creates suction on the exit end of the turbine which draws steam through the turbine from the inlet. 


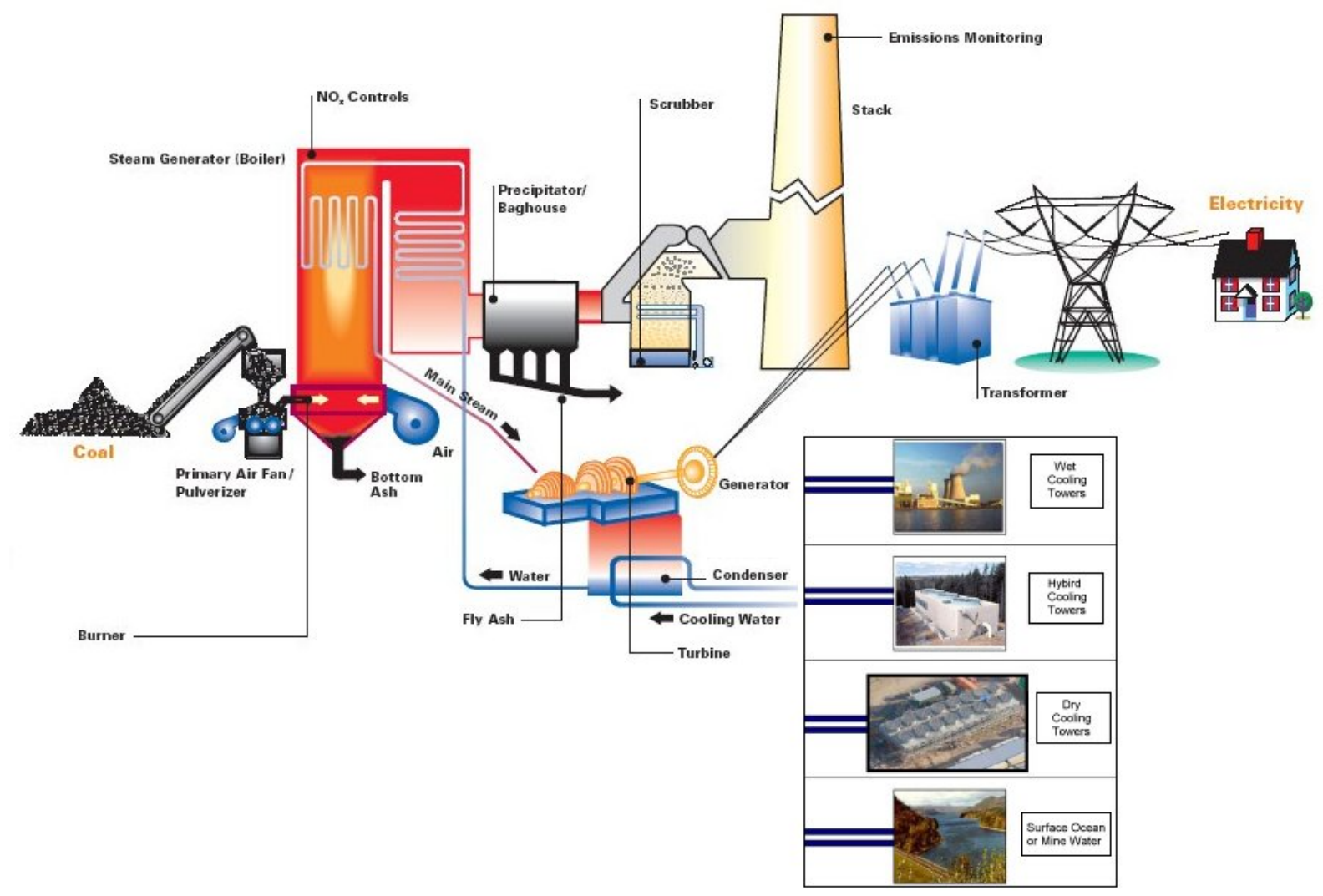

Adapted from http://umw.eei.org/industry_issues/environment/air/New_Source_Review/coal1.pdf

Figure 3: Simplified power plant cooling system

The primary purpose of the thermoelectric plant cooling loop is condensation of steam at the turbine exit to increase the draw. The most prominent cooling technologies used today are once-through systems and recirculating wet cooling towers. Recently, dry cooling systems have seen tremendous growth. While all three systems require some kind of cooling fluid, typically water, the amount of water withdrawal needed for each technology varies. Although once-through systems have the largest volume of water withdrawal, they are one of the most efficient cooling systems for power generation and tend to have the lowest capital investment costs. Wet cooling towers require lower water withdrawals than once through systems, but may require significant pretreatment for makeup water and have higher capital costs. Moreover, water vapor plumes exiting the tower can present aesthetic concerns as well as other issues. While dry cooling systems have negligible water withdrawals, they are the least efficient of the three systems because of the higher ancillary power required to operate pumps, fans, and other equipment. Dry systems also tend to have higher capital costs and larger footprints than most other cooling options. 


\section{Present trends of the cooling market}

Between the 1960s and the 1990s, wet-cooling systems dominated the cooling market. Dry cooling was primarily used for power plants located in areas with very restricted water resources. After 1990, the factors driving the use of dry cooled power plants have drastically changed. The world market for dry cooling has multiplied by about 20 times in the last 13 years. Figure 4 presents a chart showing this evolution.

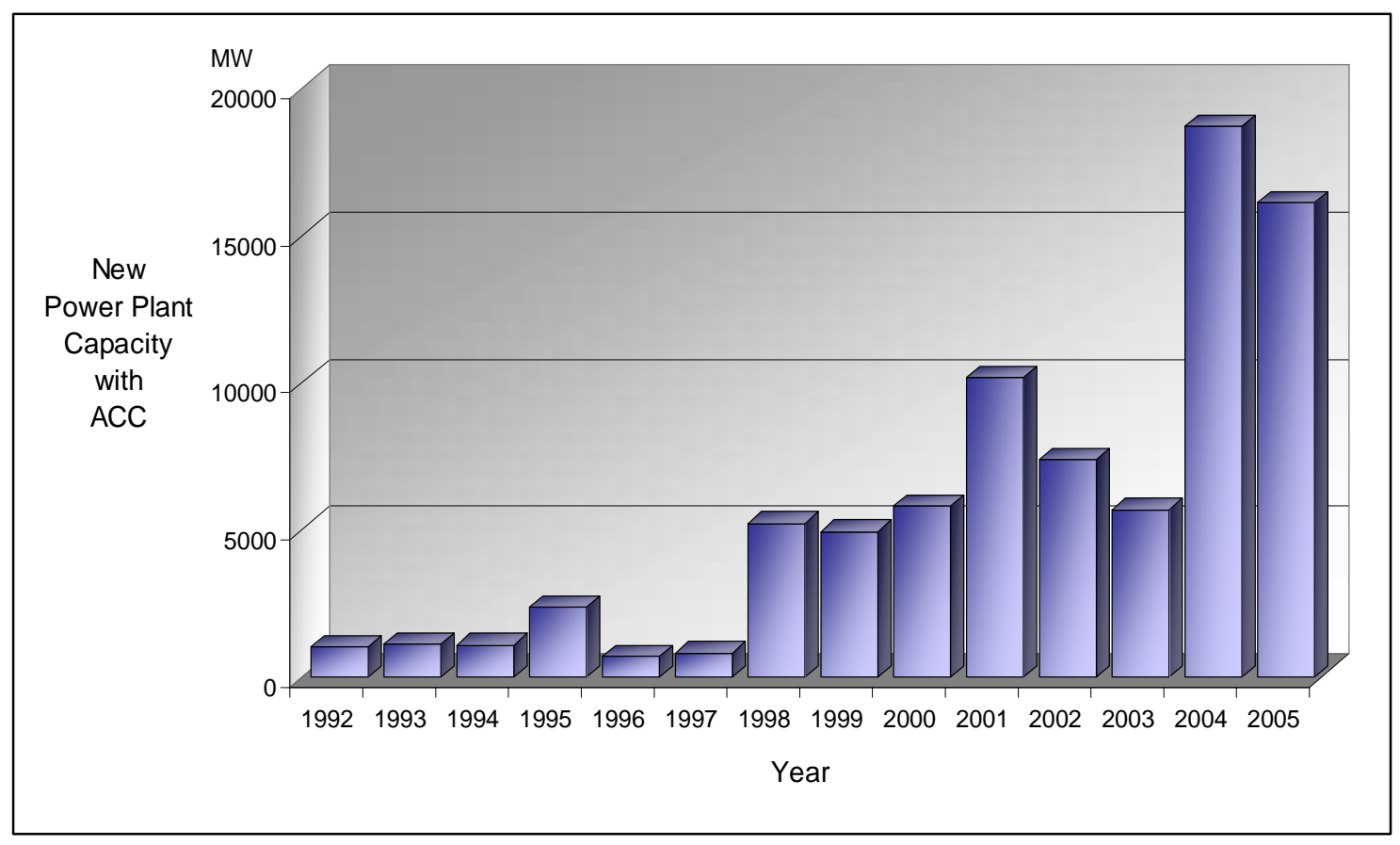

Figure 4: World Market Evolution for large Power Plants with ACCs

Many other reasons, besides water scarcity, are considered in today's selection of dry cooling systems. Some of the reasons are, for example,

- Environmental regulations regarding water saving.

- Environmental regulations, limiting the temperature, increase in rivers and seaside.

- Local regulations favoring equipment without a plume discharge.

- Flexibility in the selection of the power plant site.

- Life expectancy exceeding power plant life with reduced maintenance, no use of water treatment chemicals and no need for fire protection system.

- Shorter lead-time for power plant permits.

SPX Cooling Technologies, Inc. (SPX CT), as the largest cooling tower manufacturer in the world, has seen a tremendous growth in the dry cooling market. Figure 5 is an illustration showing recent power plants in Europe that use ACCs 
supplied by SPX CT. Figure 6 is a similar illustration of power plants operating with

SPX CT equipment in North America.

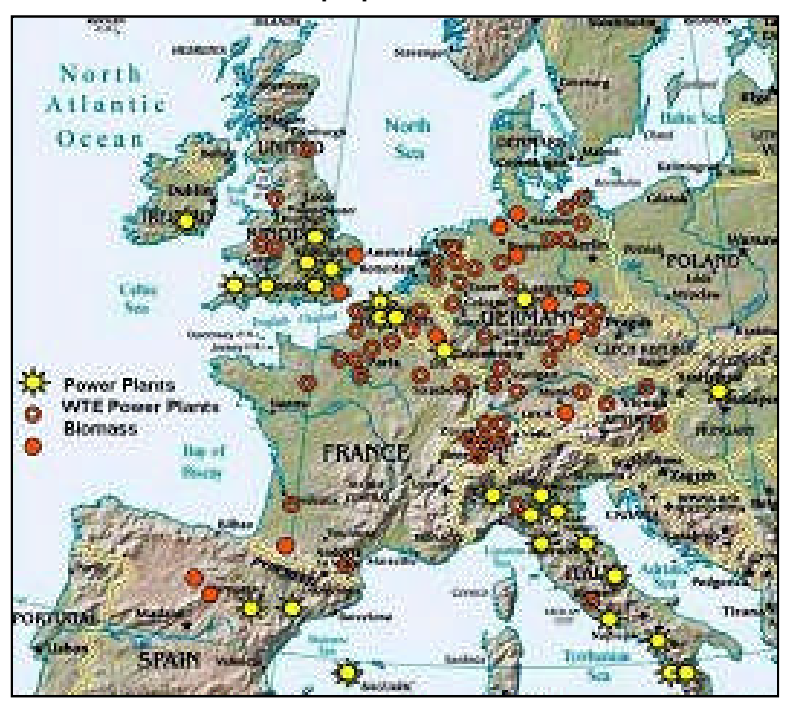

Figure 5: Europe, some large Power Plants with SPX ACCs.

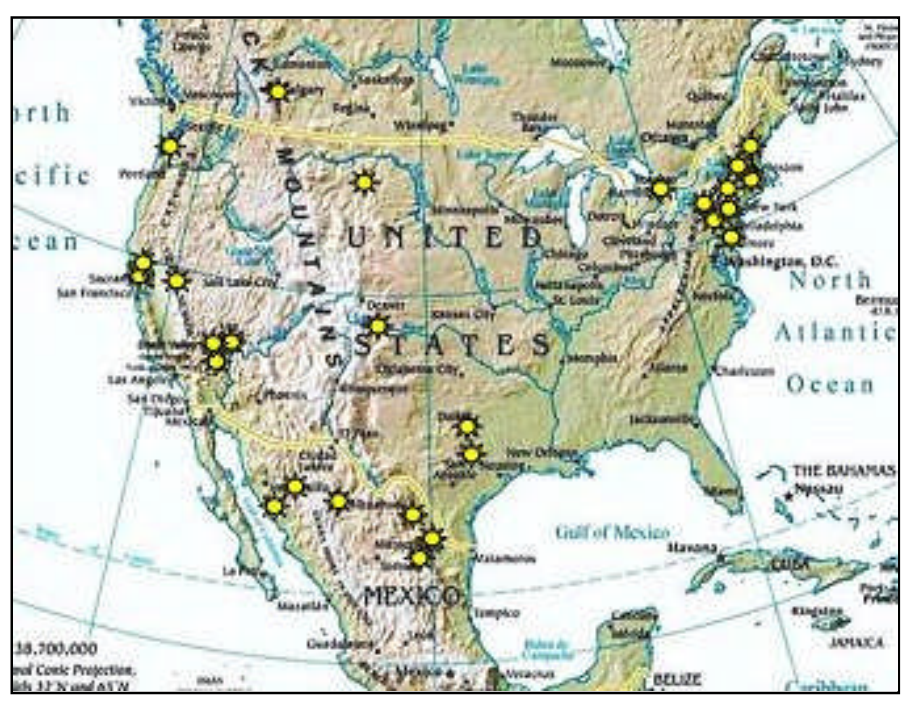

Figure 6: USA, some large Power Plants with SPX ACCs.

Technical Approach In response to the DOE funding opportunity (number: DEPS26-08NT00233-01) area of interest 1: Advanced Cooling Technology, SPX Cooling Technologies, Inc. proposed adding the SPX wind guide technology to improve the thermal performance of an ACC.

\section{The state of art of ACC}

There are two types of dry cooling systems, indirect dry cooling and direct dry cooling. For an indirect dry cooling system, steam coming out of the turbine is

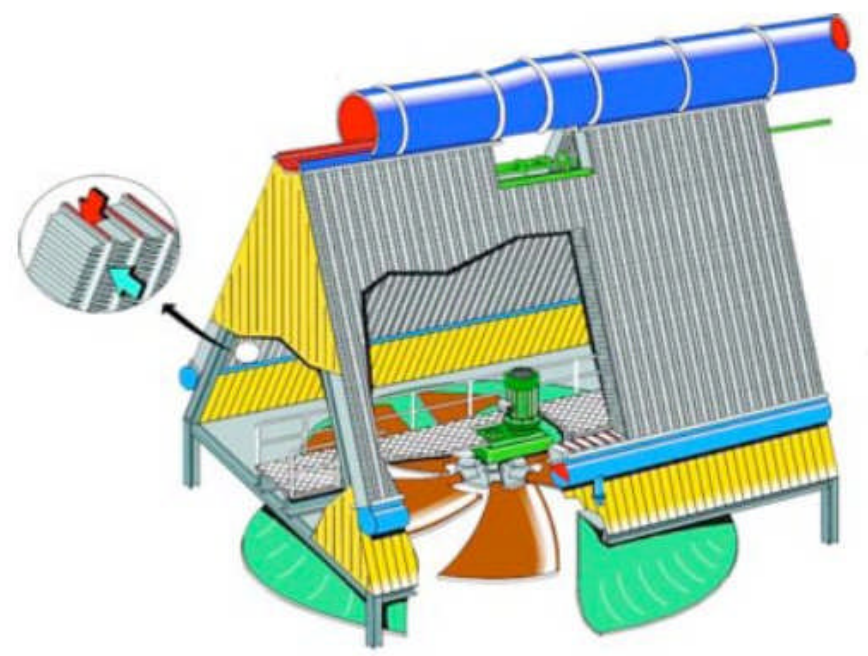

Figure 7: ACC with mechanical draft 
condensed in a surface condenser fed by cooling water. The cooling water is then pumped to tubular heat exchangers having an external finned surface and cooled by the circulation of ambient air over the fins. A direct dry cooling system, also called Air Cooled Condensers (ACC), is illustrated in Figure 7. Steam coming from the turbine exhaust enters a steam distribution manifold located on top of the structure. The steam is then distributed in several bundles arranged in a "roof structure" with an A-shape configuration. Flowing down inside the tubes, steam condenses due to the effect of ambient air drawn over the external finned surface of the tubes by the fans. The fans are located at the bottom part of the Ashape framework and blow air upwards in a forced draft configuration.

Condensate flows outside of the tubes to a condensate manifold and then is collected in a condensate tank, before being pumped to the conventional feed heating plant, or to the boiler.

Figure 8 shows an ACC supplied by SPX in Coahuito, Mexico. A typical A-frame module is illustrated in Figure 9.

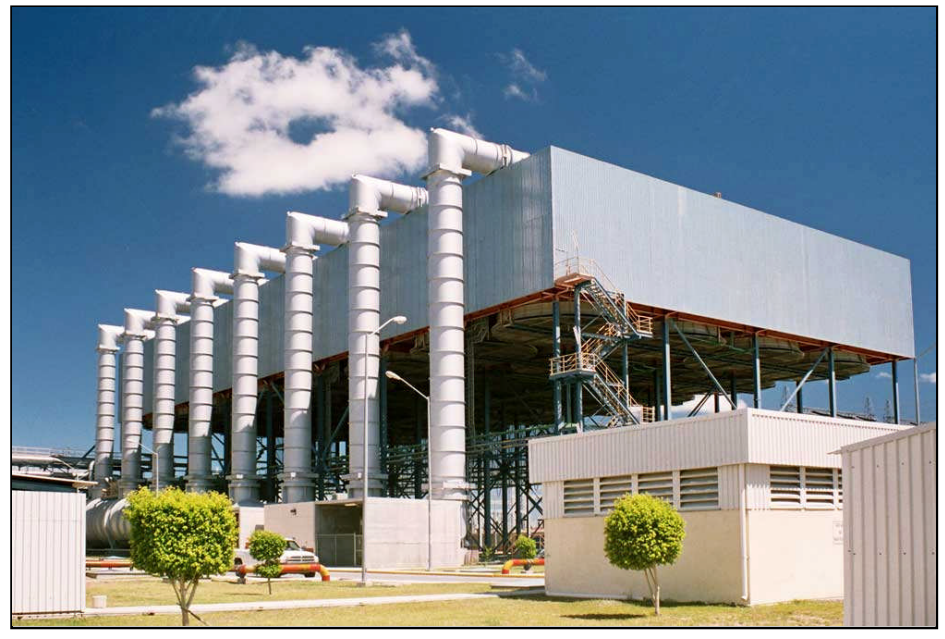

Figure 8: ACC supplied by SPX in Coahuito, Mexico

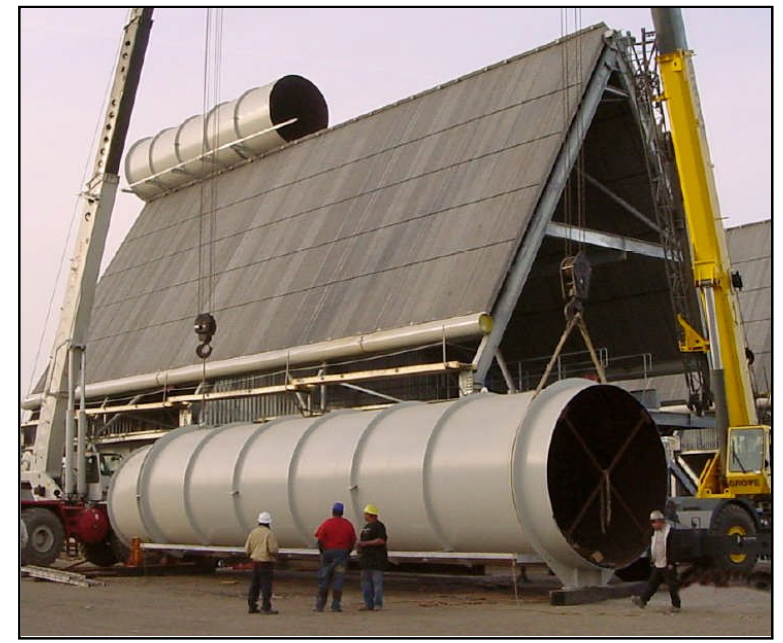

Figure 9: ACC module by SPX

\section{The effects of wind on ACC performance}

As the use of ACC becomes more popular, the importance of ensuring adequate and predictable cooling performance becomes more critical to the efficient operation of the power plant and eventually the network. A major uncertainty of an ACC performance is the effect of wind. This can be especially problematic at sites where high wind occurs concurrently with the highest ambient temperatures, a situation frequently encountered in the Southwest of United States. 
Due to ACC's forced draft configuration, its performance is highly depended on the ambient wind conditions. Two major wind effects on ACC performance are recirculation and degradation of fan performance. Maulbetsch, J. and et al. ${ }^{[4]}$ conducted a study of wind effect on ACC performance at five power plants in the Western United States. Turbine backpressure of a southwestern power plant equipped with an ACC was monitored in a period of several months. As shown in Figure 10, the difference in turbine exhaust pressure between low speed $(<4$ $\mathrm{MPH}$ ) and high speed ( $>20 \mathrm{MPH}$ ) winds ranges from 1 to 2 inches Hga at higher $\left(>90^{\circ} \mathrm{F}\right)$ ambient temperatures.

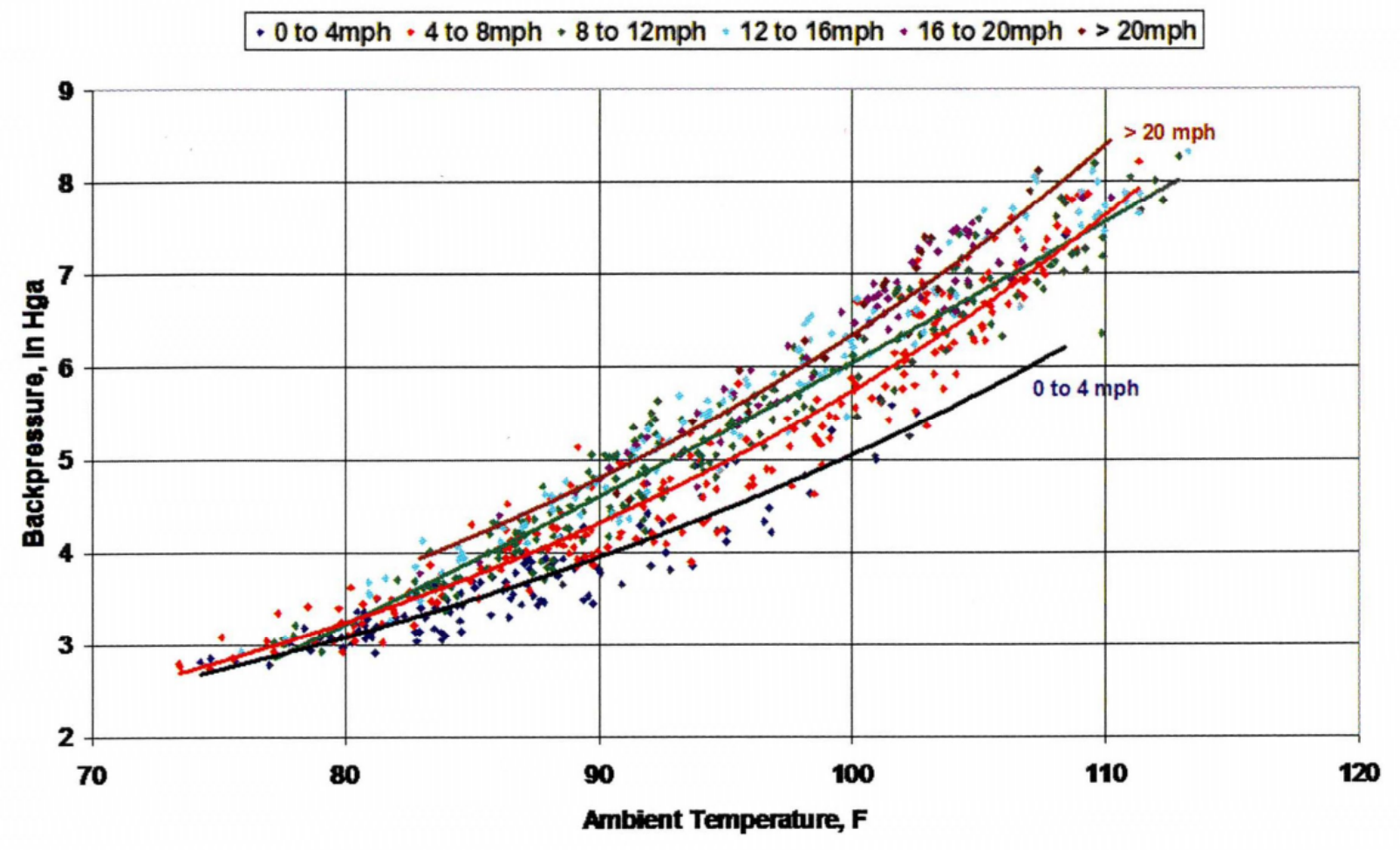

Figure 10: Effects of wind on ACC performance ${ }^{[4]}$

The average recirculation measured at the five sites is typically $3^{\circ} \mathrm{F}$ or less, which would account for only about 0.5 inches $\mathrm{Hga}$ in increased backpressure. They concluded that recirculation is not the sole, or even the major, cause of ACC performance degradation under windy conditions. In the fan performance measurement, they discovered that the reduction of fan CFM was as much as 50 to $60 \%$ on the upwind cells.

The objective of this proposal is to improve ACC performance by using SPX wind guide technology. 


\section{SPX wind guide technology}

ACC fans are typically large diameter ( 10 meters), low speed ( $100 \mathrm{rpm})$ axial flow fans with modest static pressure rise ( 0.3 to 0.5 inches of water). The fans are normally surrounded by bell-shaped inlet shrouds in order to minimize inlet losses. The optimum operating condition for the fan is a uniform airflow entering normal to the inlet plane. A cross wind reduces fan performance both by introducing a turning loss into the inlet and by causing a non-uniform flow distribution across the inlet plane.

SPX CT has spent several years studying the crosswind effect on ACC fan performance. Computational fluid dynamics (CFD) was used to model the ACC performance at various wind speeds and directions. Figure 11 shows an ACC model layout.

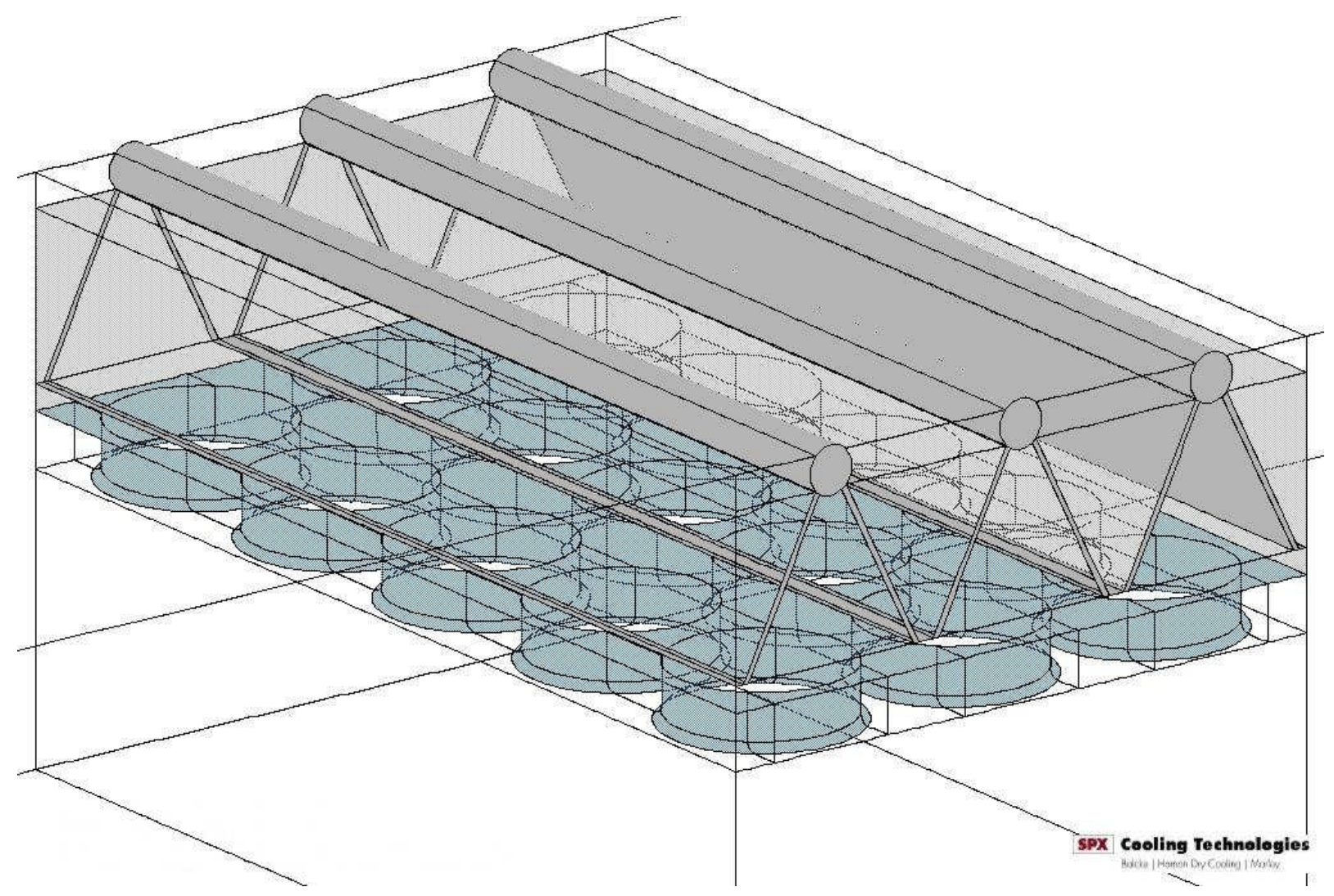

Figure 11: ACC model layout

In this particular model, the ACC unit has three streets and five fan cells per street. Three A-frame fin coils sit above the fan deck. Fans blow air upward and force it passing through the fin coils. Under no wind condition, fans are rated to overcome the resistance of the fin coil and deliver required CFM for the design cooling duty. 
The CFD plot of airflow distribution under no wind condition along the cross section of center three cells is given in Figure 12. Colors represent Z-component velocity. It can be seen that air- flow is relatively well distributed in three fans.

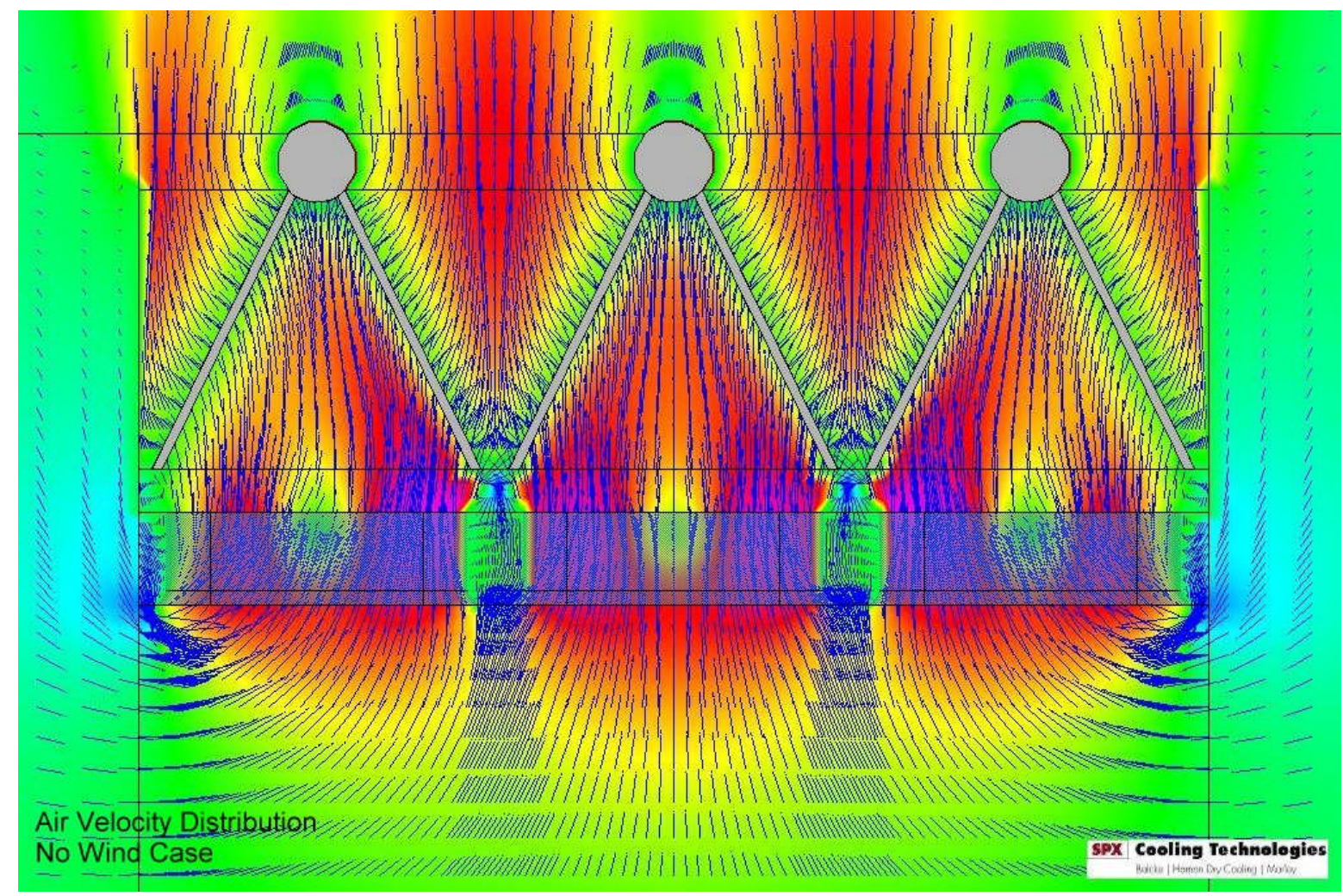

Figure 12: ACC airflow distribution under no wind condition

When a 20 miles/hour quartering wind is applied, the air distribution across fans becomes uneven. The upwind fan gets a dramatic distortion. A significant reduction of total fan CFM of the unit is predicted by the CFD modeling. Figure 13 shows the ACC airflow distribution at 20 miles/hour quartering wind. Significant airflow distortion in the upwind fans are indicated.

In order to improve fan performance under wind, a number of wind screen and wind guide configurations were investigated using CFD. Two wind guide configurations were found to be the top performers. Both configurations add guide vanes to the ACC unit.

The first configuration adds a guide vane at fan deck level. The guide vane projects outwardly and downwardly from the perimeter wall of the unit. The second configuration adds another guide vane at the middle of the air inlet. It is parallel to the first guide vane. Its width is the same as the first guide vane. 


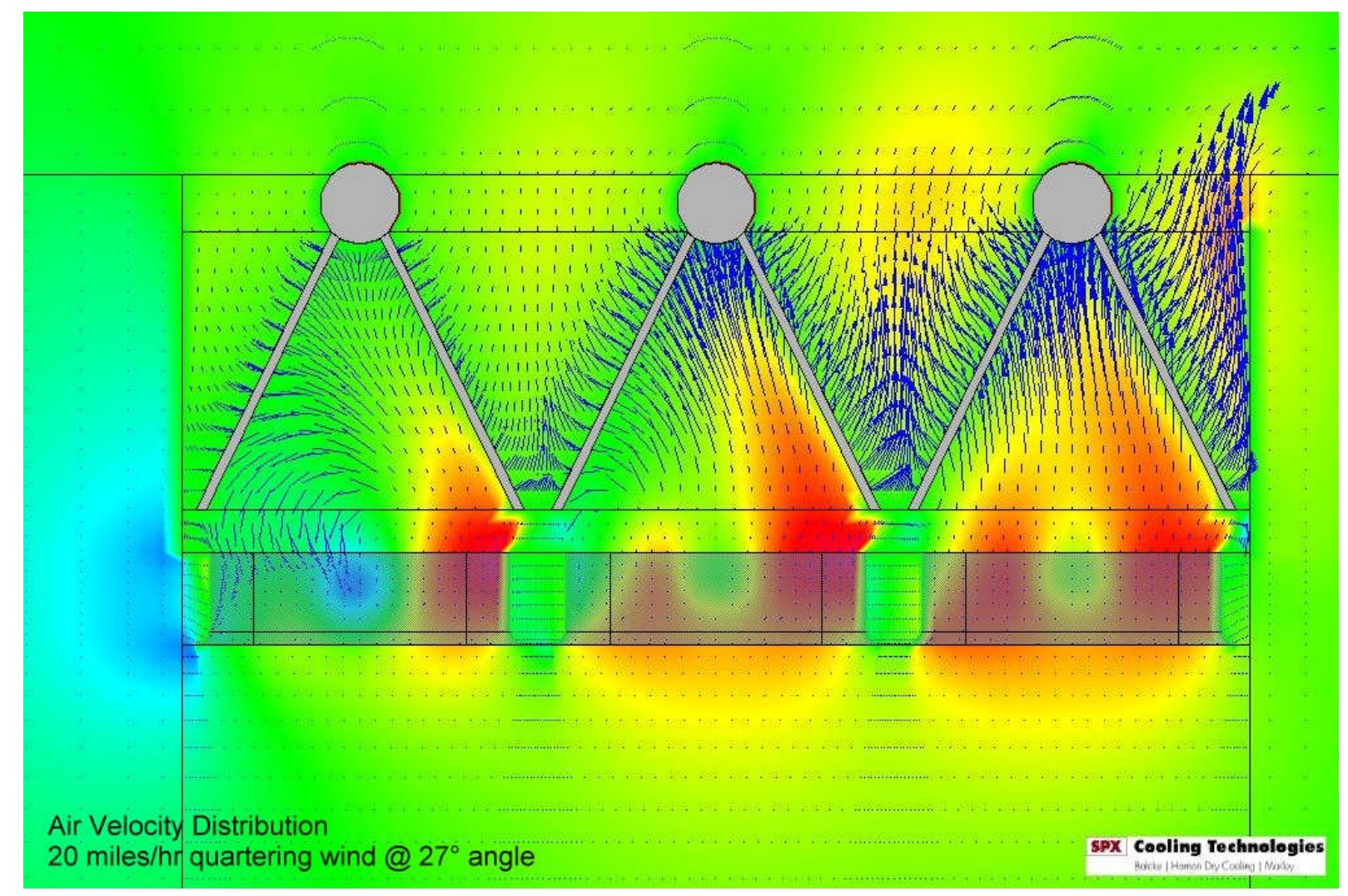

Figure 13: ACC airflow distribution at 20 miles/hour quartering wind

The wind guide package tends to reduce the crosswind effect by directing air towards the fan. This works not only on the windy condition but also at no wind condition. The preliminary CFD modeling indicates the total fan CFM of the unit increases $7 \%$ at no wind condition. Figure 14 shows the ACC airflow distribution at no wind condition when wind guides are installed. Airflow improvement on the perimeter fans is indicated.

At 20 miles/hour quartering wind, a great air flow improvement on the upwind cell is predicted by using wind guides. The CFD modeling indicates $10 \%$ total fan CFM improvement at 20 miles/hour quartering wind condition. That is roughly $5 \%$ improvement on ACC thermal performance. Figure 15 shows the ACC airflow distribution at 20 miles/hour quartering wind when wind guides are installed. Significant airflow improvement on the perimeter fans is indicated. 


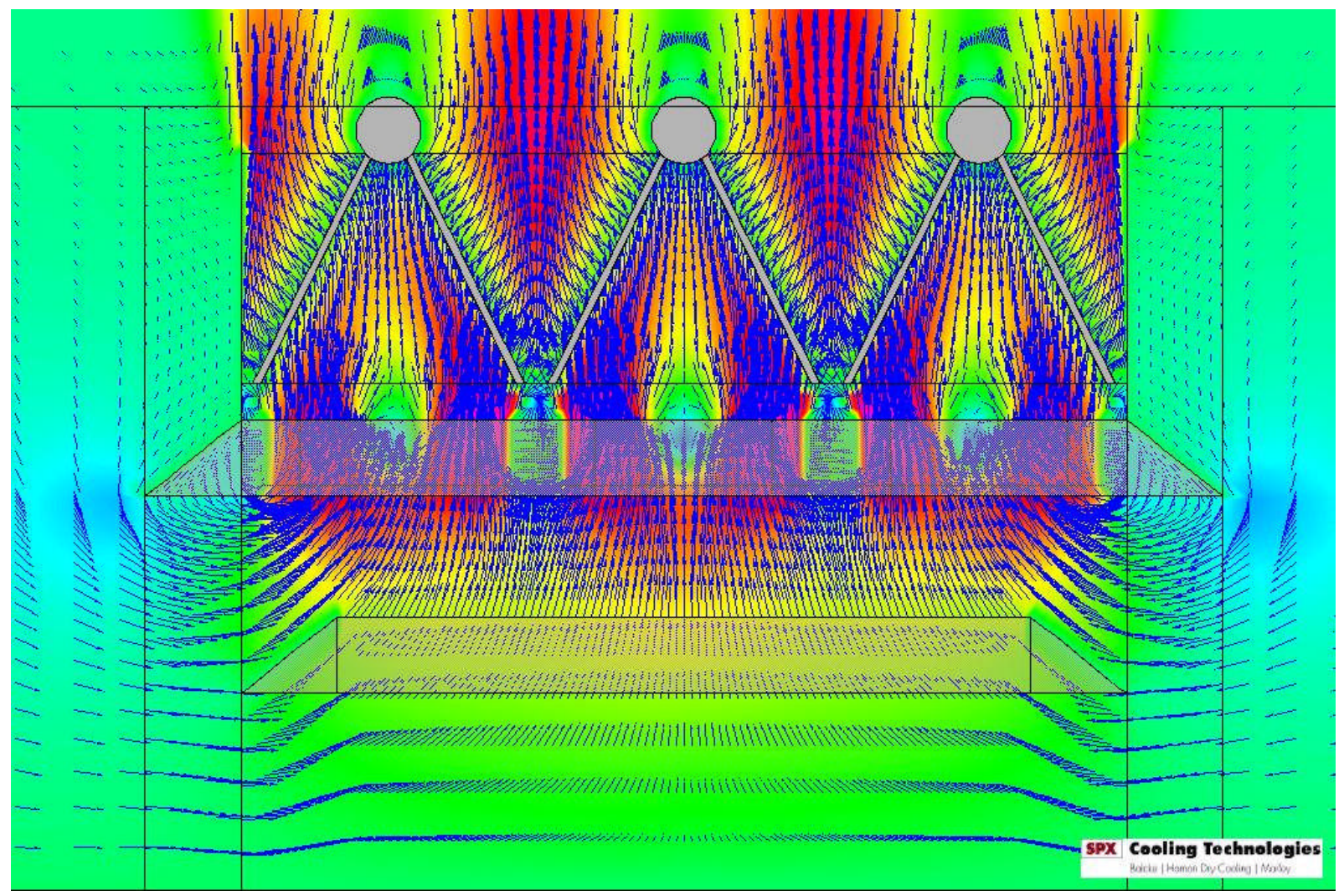

Figure 14: ACC airflow distribution at no wind condition when wind guides are installed 


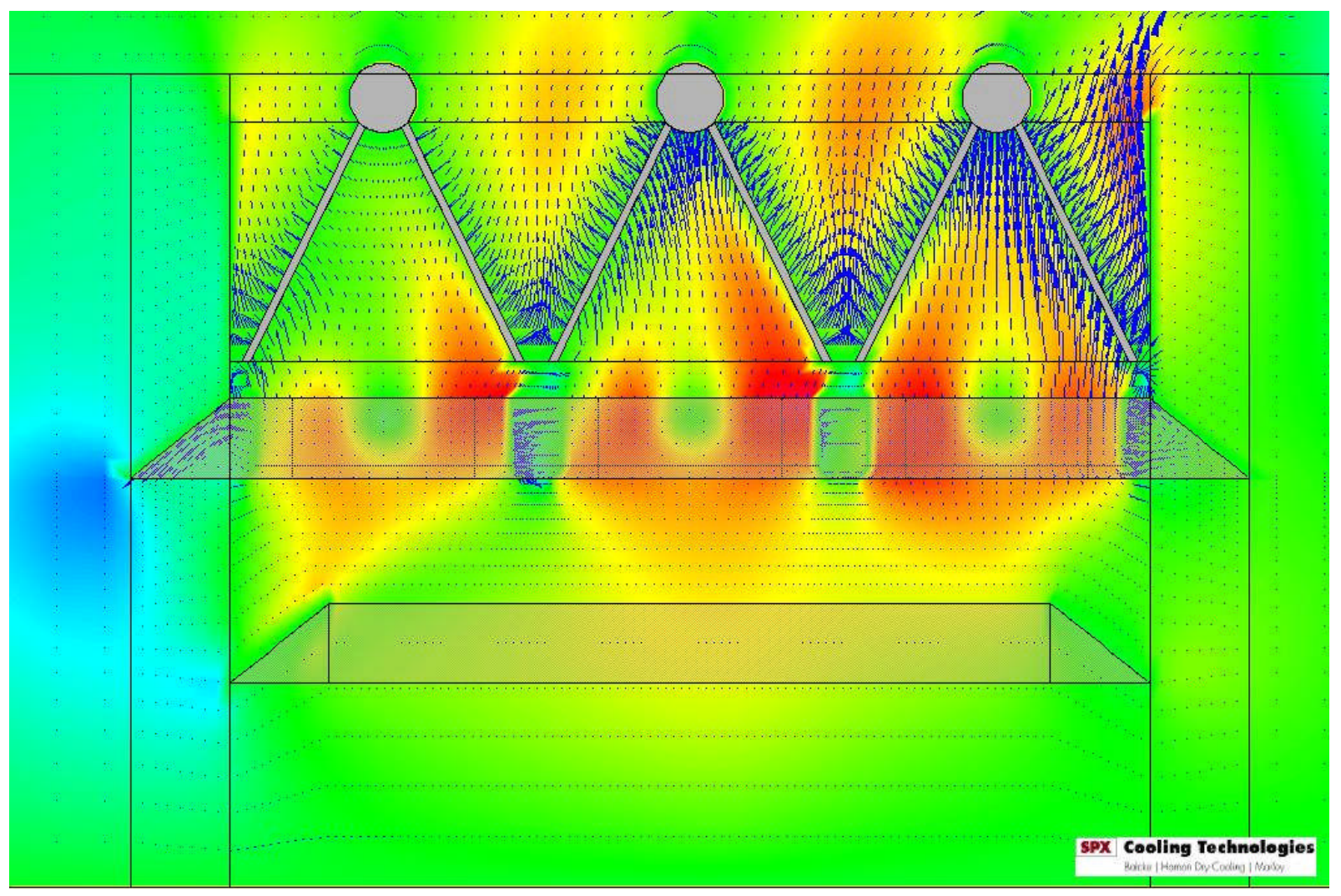

Figure 15: ACC airflow distribution at 20 miles/hour quartering wind condition when wind guides are installed

Schedule - This project is proceeding on schedule per the milestones below, completing the goals as laid out.

Description - This project is aimed at reducing the efficiency variation of ACC cooling in significantly windy conditions, defined as $10-30 \mathrm{mph}$ at the power plant site. SPX

Cooling has developing physical enhancement to the base ACC unit to improve airflow in windy conditions. The efficiency enhancement potential of a recently developed addon technology, on dry cooling processes is predicted to be significant. A pilot-scale test is being executed here to determine effectiveness of this solution.

The project has now added this new technology to an existing ACC cooling process at a selected coal-fired power plant, providing for the ability to quantify the plant efficiency improvement for the main plant cooling process. Such an efficiency improvement in Dry Cooling would represent a major advance for plants looking to select or enhance cooling technologies at power plants today.

This project application was submitted in April 18, 2008 with a budget established for a particular modular assembly design. As the project was erected, it became clear that 
that original design needed additional field work to be viable as a long-term ACC addon. SPX Cooling executed the modifications in the field and actually improved the original schedule.

\begin{tabular}{|c|l|l|}
\hline Item & Milestone Description - DEFC2606NT06549 & Scheduled Date, Status \\
\hline 1 & Partner w/Utility: Host Site Agreement & $1 / 09$, COMPLETE \\
\hline 2 & Model Existing ACC Condition & $4 / 09$, COMPLETE \\
\hline 3 & Monitor the Existing ACC Performance & $7 / 09$, COMPLETE \\
\hline 4 & Install Modification & $8 / 09$, COMPLETE \\
\hline 5 & Evaluate Resulting ACC Efficiency Improvement & $11 / 10$, COMPLETE \\
\hline 6 & Reporting & $12 / 10$, COMPLETE \\
\hline
\end{tabular}

Results: ACC Monitoring and Thermal Performance

CFD Modeling - The existing ACC at Black Hill Power WyGen Unit 2 was modeled in CFD. Figure 16 shows the 3-D view of air flow discharged from fans. The 3-D surface in the figure is an iso-surface of air velocity at $6 \mathrm{~m} / \mathrm{s}$. Fans along the perimeters of the ACC facing wind direction are suffered by the impingement of wind. 


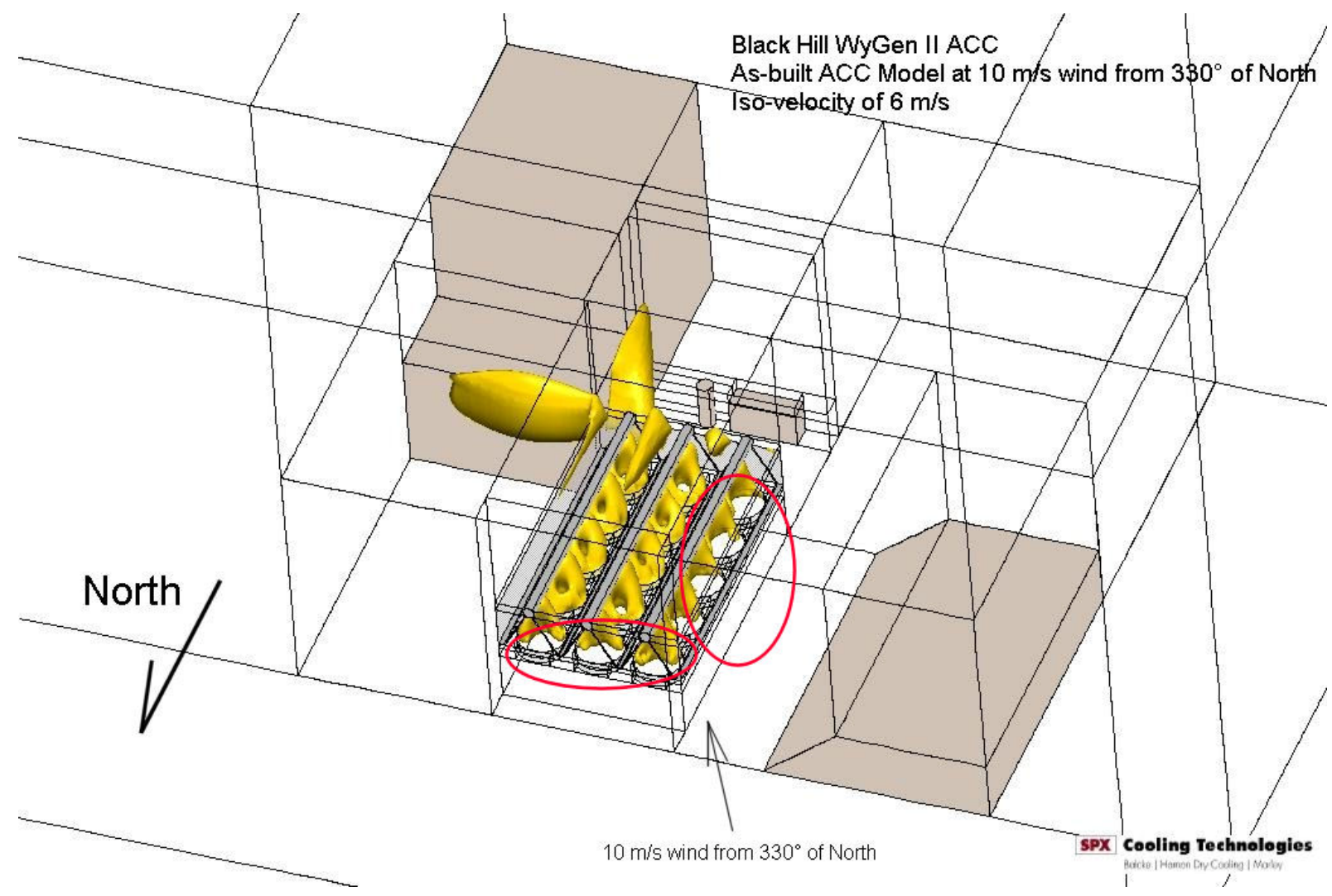

Figure 16 A 3-D view of air flow of the existing ACC at $10 \mathrm{~m} / \mathrm{s}$ wind $(22.4$ miles/hour $)$

The CFD model was then modified with SPX wind guide technology. Figure 17 shows the air flow of the ACC at the same wind speed and direction. Improvement of the air flow on the perimeter fans can be seen. 


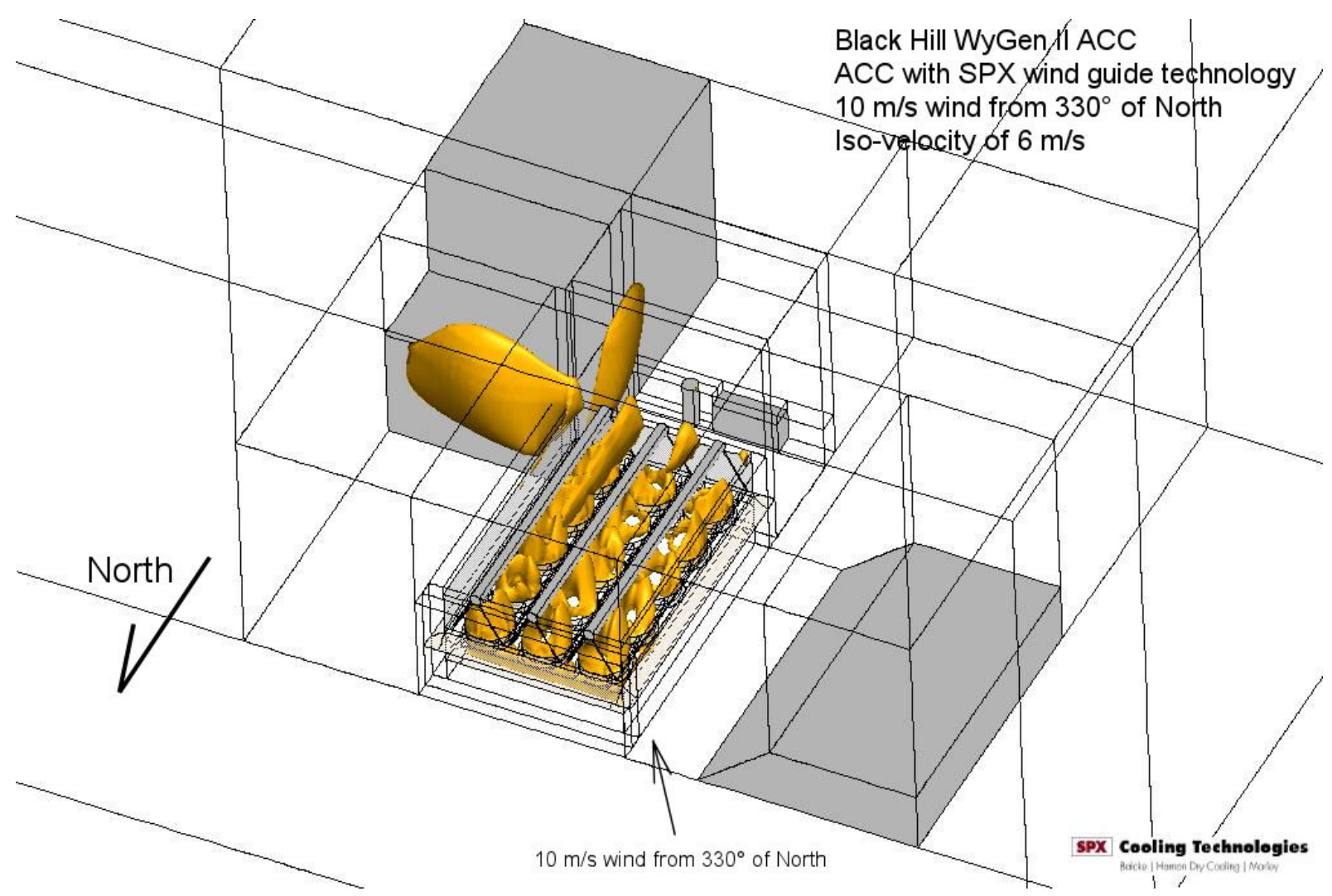

Figure 17 A 3-D view of air flow of modified ACC with wind guide at $10 \mathrm{~m} / \mathrm{s}$ wind $(22.4$ Wind Guide installation miles/hour)

The modeled 2 level Wind Guide was installed on the Black Hill WyGen Unit 2 ACC during August, 2009, as shown in the photograph below:

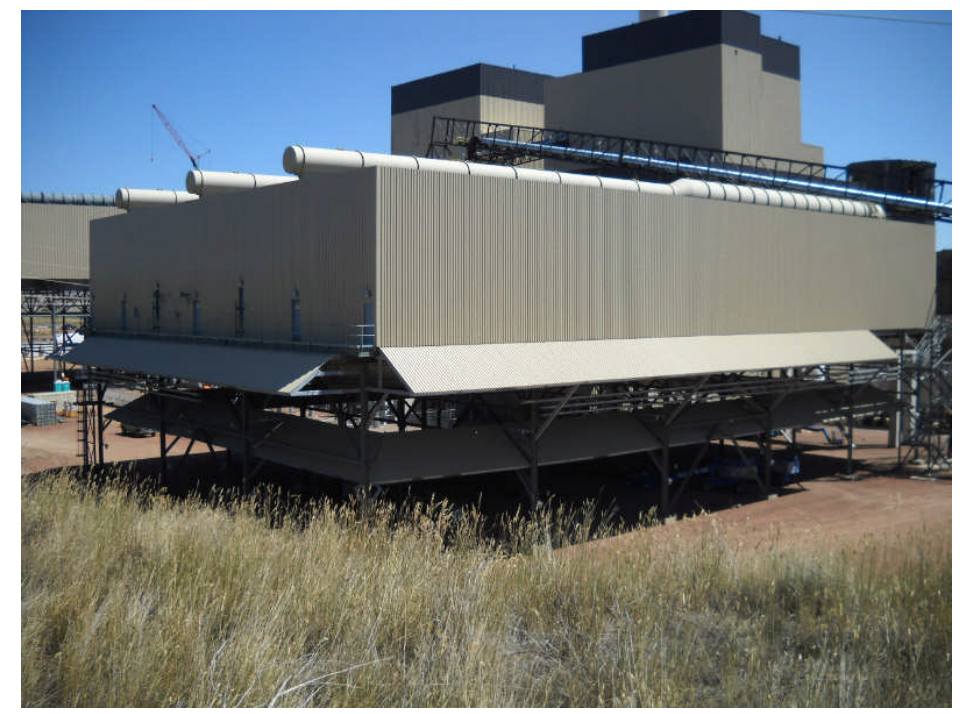

Wind Guides as Installed 
ACC Performance Testing and Monitoring - The existing ACC of Black Hill WyGen Unit 2 was tested before any modification in order to get the baseline performance. There were 24 temperature probes (RTDs) placed at the air inlet around the ACC. Additional 15 temperature probes were placed at fan discharge. Wind speed and direction were measured using wind anemometers and wind vanes. Steam flow, steam temperature, turbine back pressure, ACC fan RPM were measured using plant instrumentation.

After over a month of testing of existing ACC in May and June of 2009, ACC was modified with SPX wind guide technology. ACC was re-instrumented with the same temperature probes. The modified ACC was tested and monitored for over two months.

Figure 18 shows the ACC thermal performance varying with wind speed before and after SPX wind guide installation. The blue dots represent the base tower thermal performance while the pink dots are the performance of modified ACC. The black line is the regression curve of the base tower data. The red line is the regression curve of the modified tower data. The yellow line is the CFD prediction.

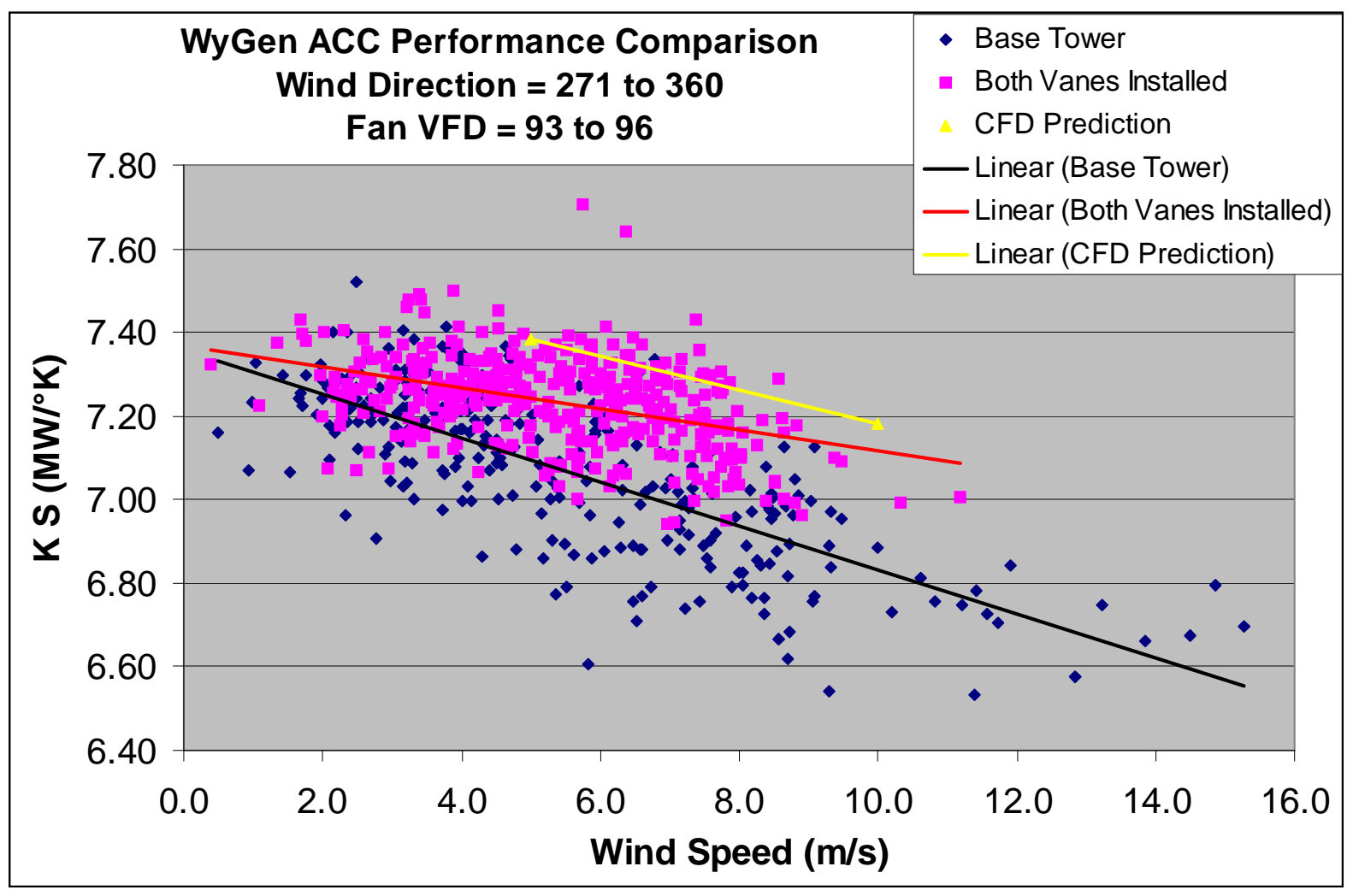

Figure 18 ACC thermal performance varies with wind speed before and after SPX wind guide installation 
The improvement of ACC thermal performance after SPX wind guide installation can be clearly seen. The benefit increases when wind speed rises. There is a $5 \%$ improvement at high wind and $1 \%$ at low wind speed.

Charts from $A$ to $D$ are bar charts showing the heat transfer coefficient improvement of the ACC at different wind directions, wind speeds, and fan RPMs. Chart A shows the improvement at wind direction in 0 to 90 degree quartern. Chart $B$ is for wind direction in 90 to 180 degree quartern. Chart $C$ is for wind direction in 180 to 270 degree quartern. Chart $\mathrm{D}$ is for wind direction in 270 to 360 degree quartern. The benefit of SPX wind guide on the ACC is shown on all wind directions.

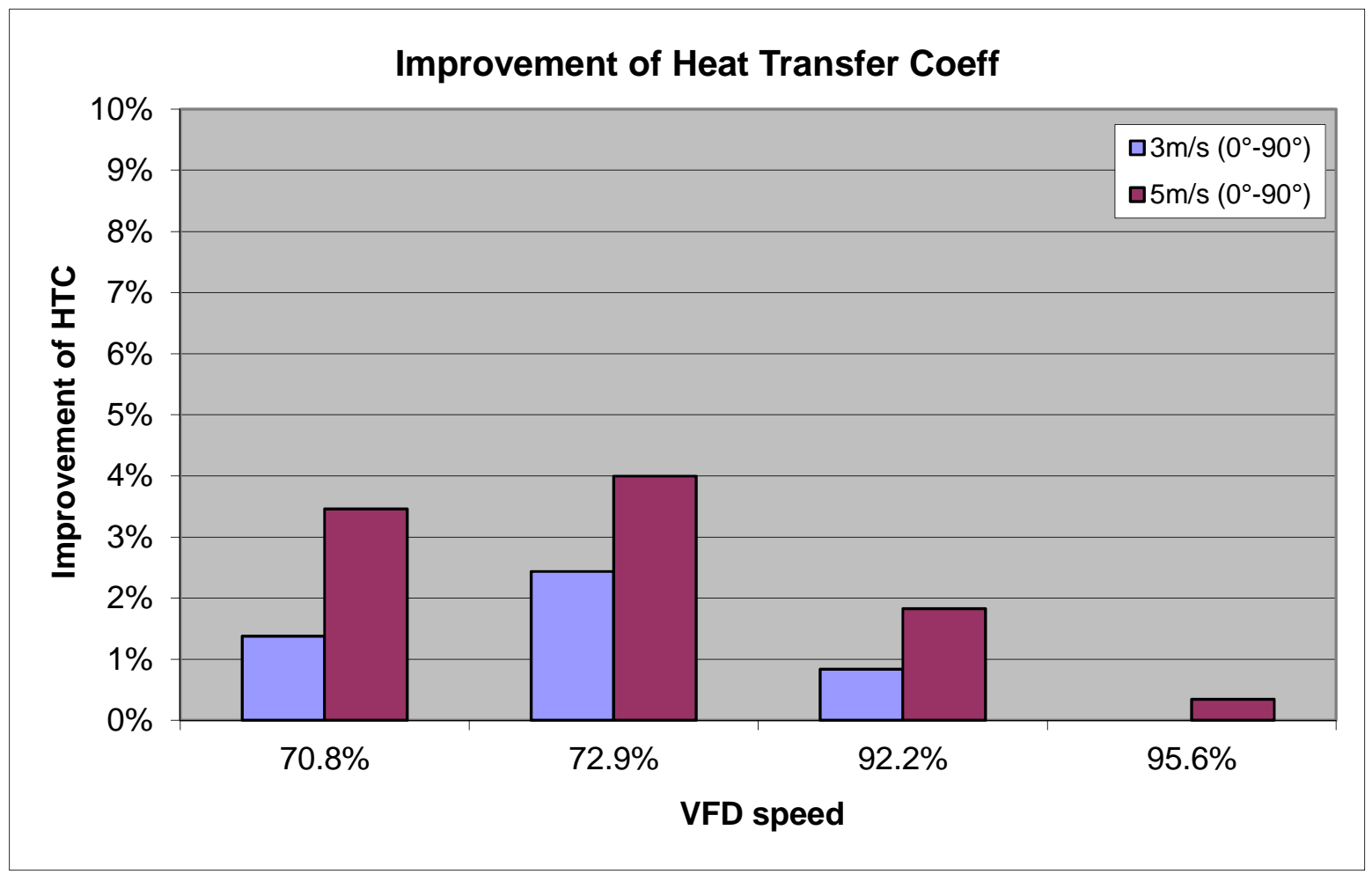

Chart A. Wind direction in 0 to 90 degree quarter 


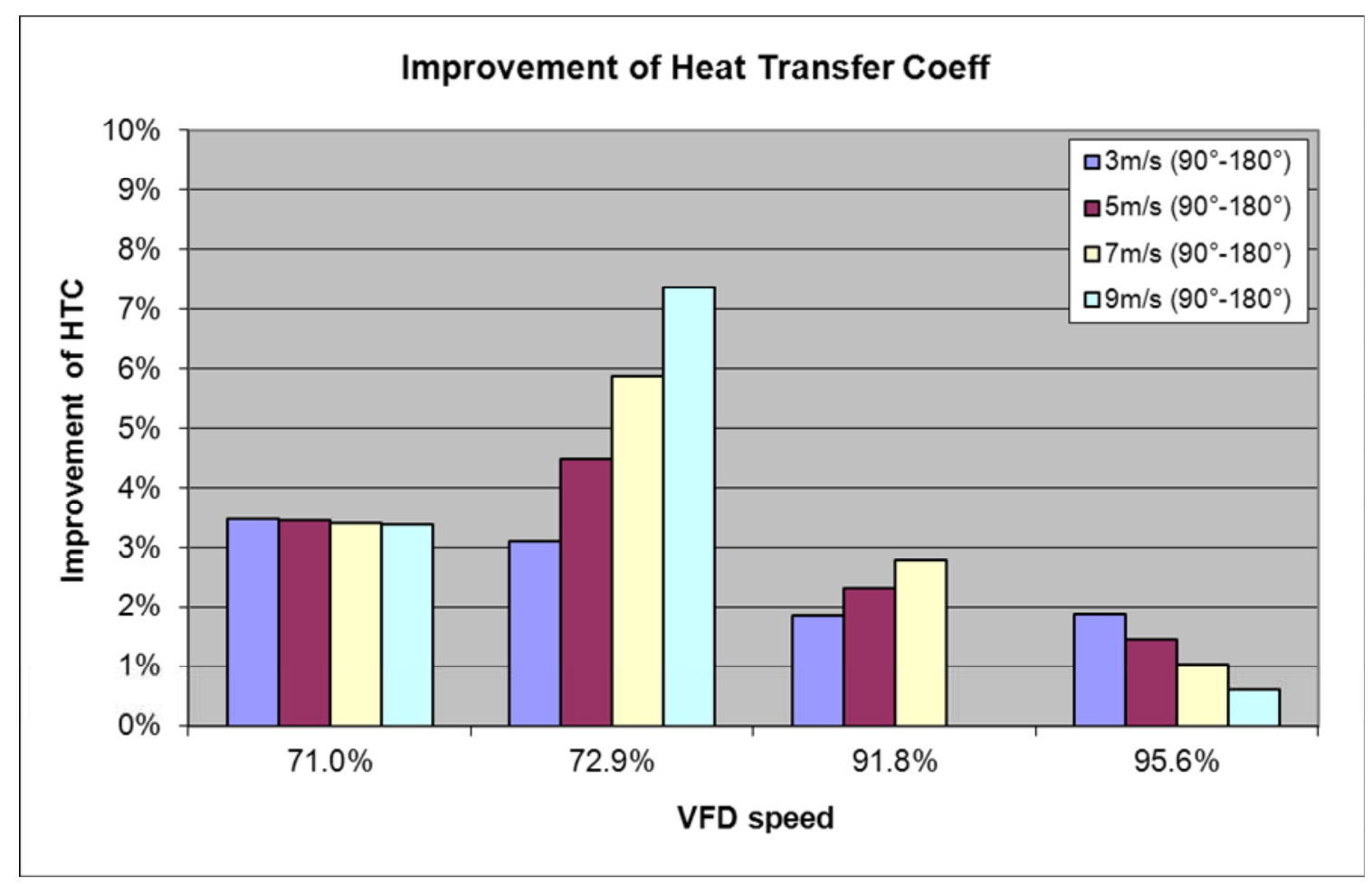

Chart B. Wind direction in 90 to 180 degree quarter

Chart C. Wind direction in 180 to 270 degree quarter

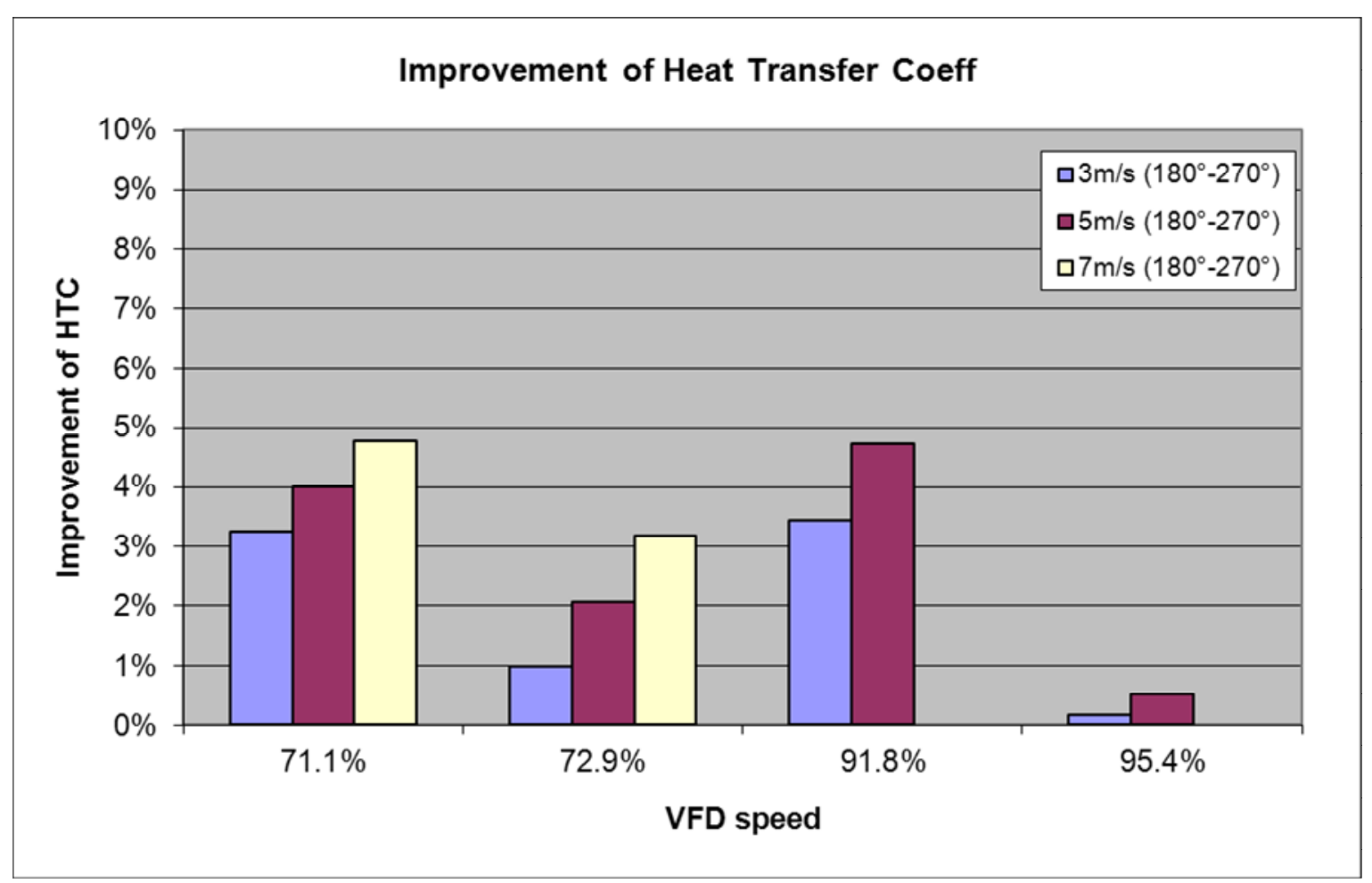




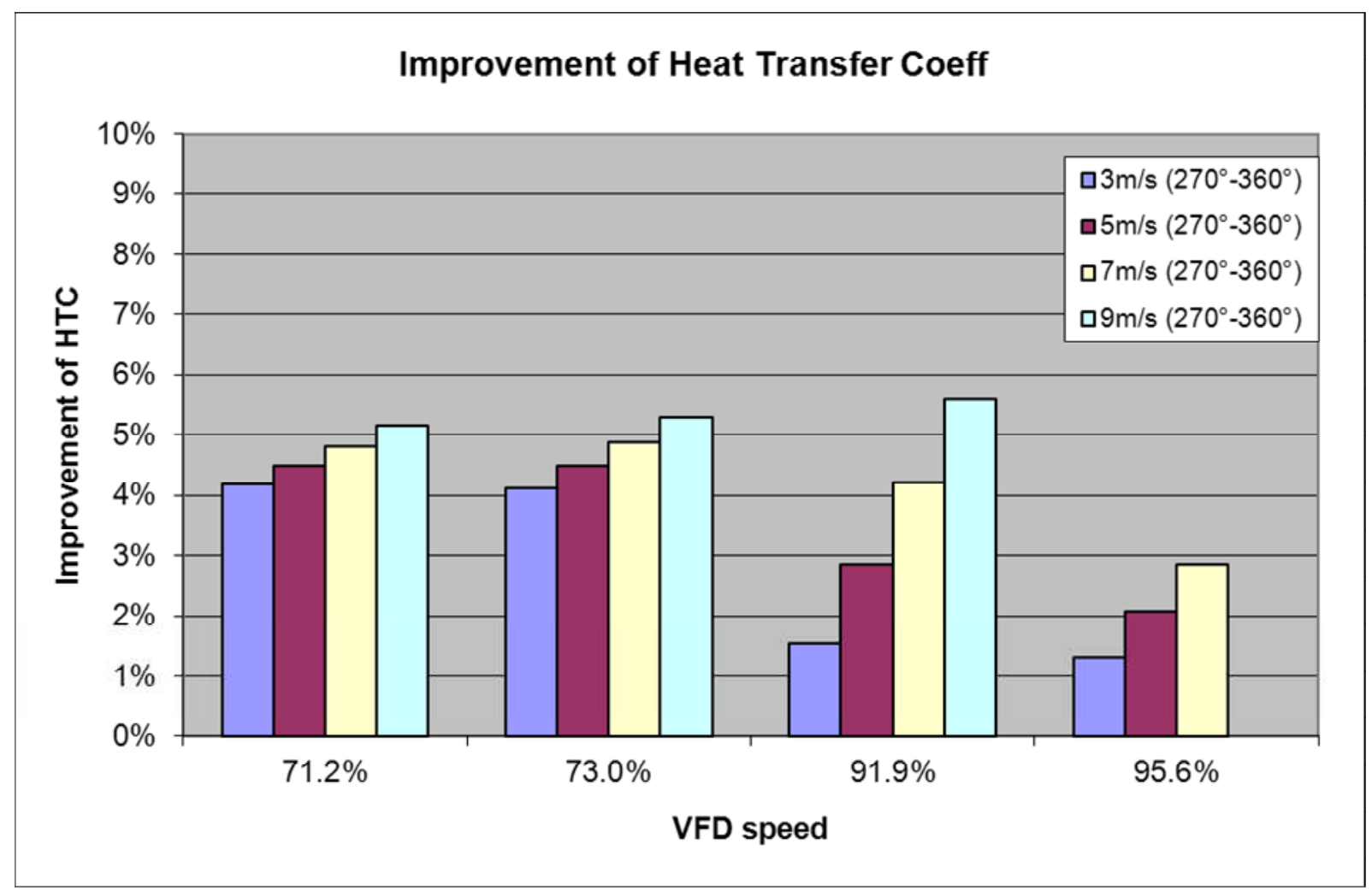

Chart D. Wind direction in 270 to 360 degree quarter

In terms of turbine back pressure improvement, Figure 19 shows the turbine back pressure varying with wind speed and air temperature at the fan. The blue surface is the back pressure when base tower (existing ACC) is used. The red surface is the back pressure after SPX wind guide is installed. It clearly shows the turbine back pressure reduction after the SPX wind guide is installed. 


\section{WyGen Turbine Back Pressure Comparis on Before and After Wind Guides Installation \\ Wind Directions from 270 to 360 \\ Fan VFD from 93 to 96}

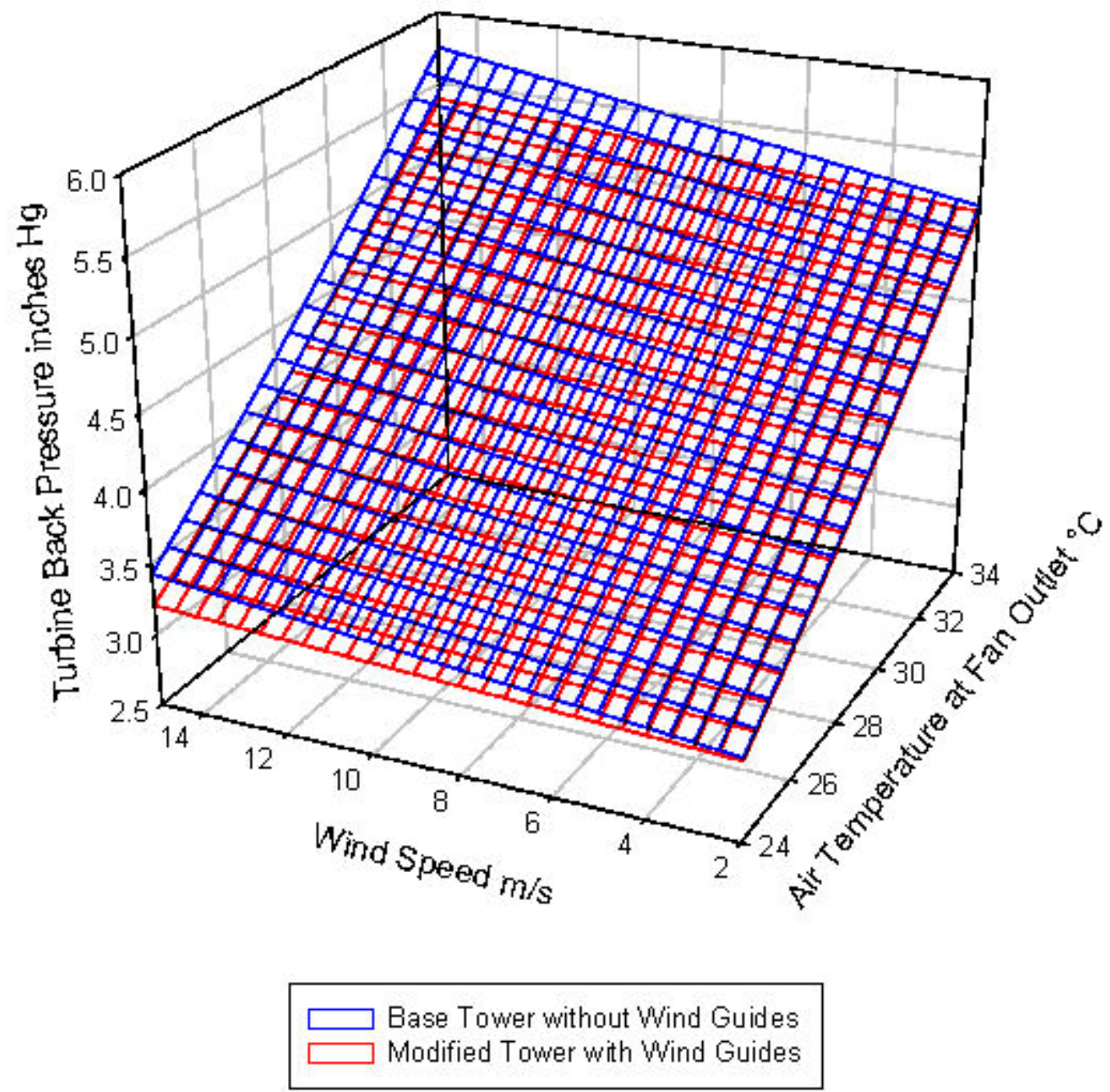

Figure 19 Turbine back pressure varies with wind speed and air temperature at the fan

Figure 20 shows the percentage reduction of turbine back pressure at various wind speed after wind guide installation. The graph also illustrates the percent reduction is a function of wind speed alone. It is not depend on the ambient air temperature. 


\section{WyGen Percent of Back Pressure Reduction \\ After Wind Guides Installation \\ Wind Direction from 270 to 360 \\ Fan VFD from 93 to 96}

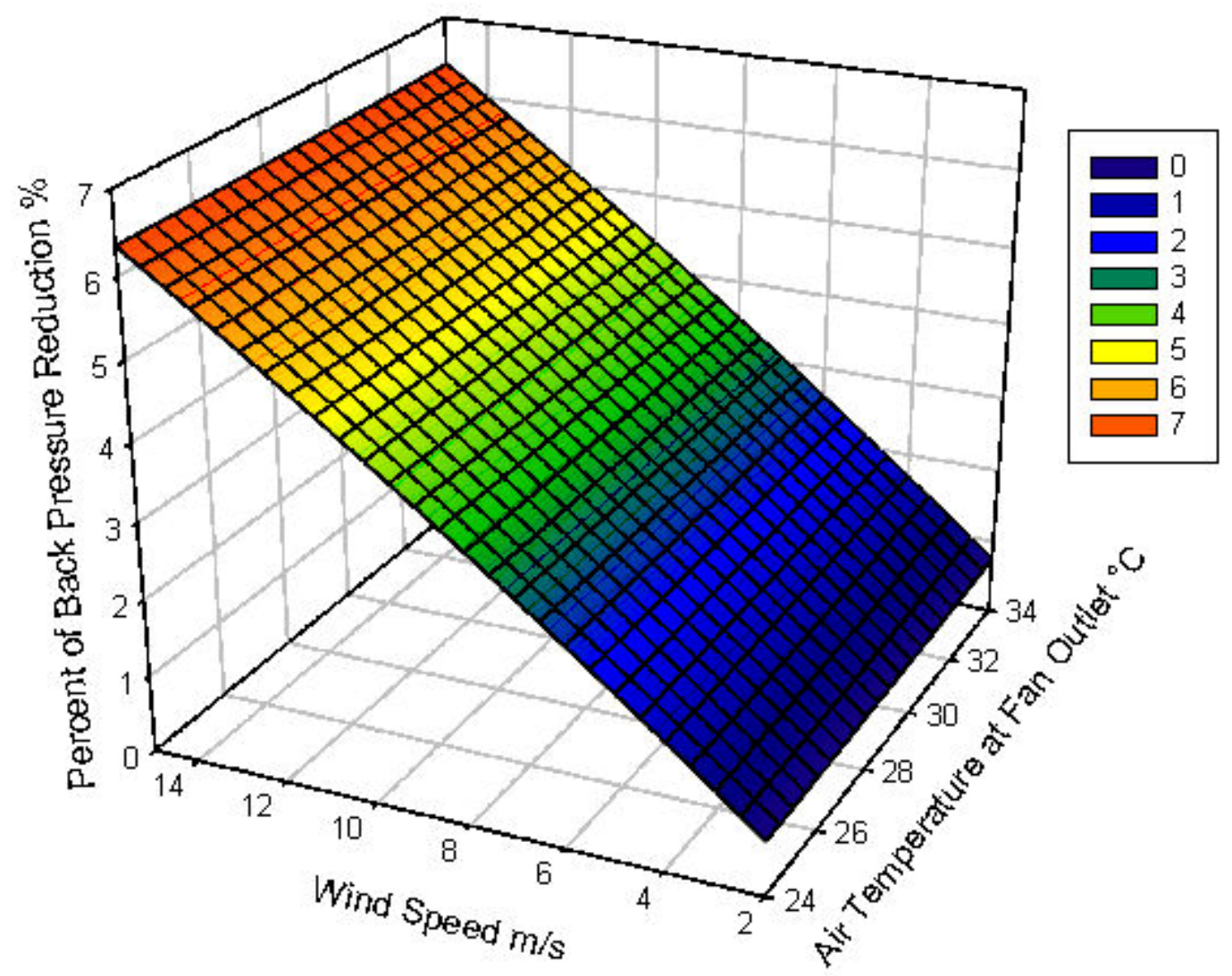

Figure 20 Percent reduction of turbine back pressure at various wind speeds

\section{Instrument Layout and Example Data}

The following pages provide a description of the test information needed to support the calculations and reach the conclusions above. A layout drawing, on page 25, shows instrument placements and the tables, pages 26-29, show example data collected from those instruments. In addition to this data, the plant provided time stamped data to correspond to our collected data.

Twenty four RTDs were installed at the inlet to record dry bulb temperatures. These are labeled on the drawing as numbers 1 through 24 . They were placed at 12 positions around the inlet and 2 heights. 
An additional 15 RTDs were placed above each fan to record dry bulb readings. These are numbered 25 through 39 on the drawing.

The steam temperature exiting the turbine was measured as close to the discharge as possible.

Wind speed and direction was measured at each inlet. These are labeled 81 through 88 on the drawing.

Ambient conditions were monitored from the top of a hill approximately 600 feet from the ACC. Recorded readings were; wind speed, wind direction, dry bulb temperature, barometric pressure, and relative humidity.

\section{Data Collection}

The data loggers monitored all parameters continually and recorded the averages for each 5 minute period.

Data from the data loggers was automatically sent to an SPX computer from the site daily via the Internet.

The data was extracted and organized in an Excel workbook in two week increments.

\section{Plant Provided Data}

In addition to this data, the plant provided time stamped data, in 5 minute averages, corresponding to the data collected above.They provided the following:

1. Ambient Temperature

2. Steam Temperature

3. Steam Backpressure

4. Condensate Flow

5. Total Steam Flow

6. Various Condensate Temperatures

7. Steam Extraction Temperatures and Pressures

8. Condensate Tank Pressure and Level

9. Valve Positions

10. Makeup Flow Rates

11. Turbine Output

12. VFD Operating Percent

13. Amps and kW of the Fans

This data was integrated into each Excel workbook in the same 2 week increments as the SPX collected data. 


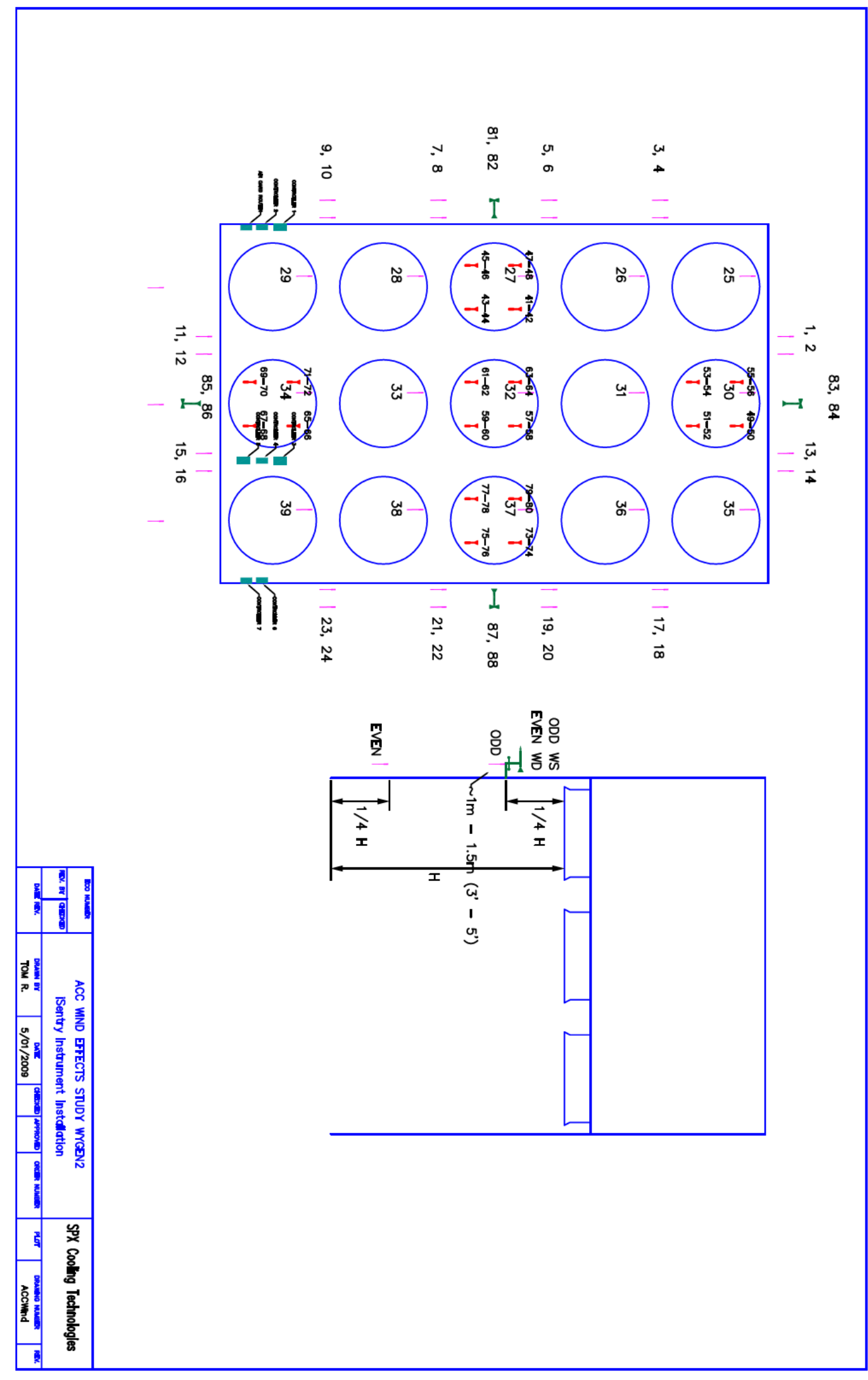




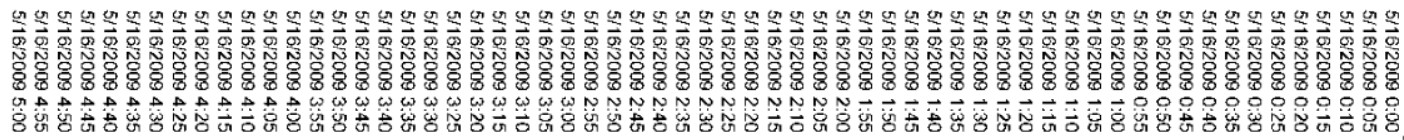

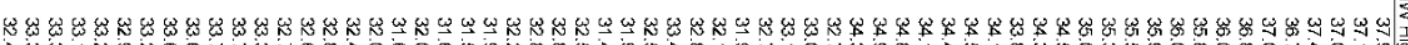

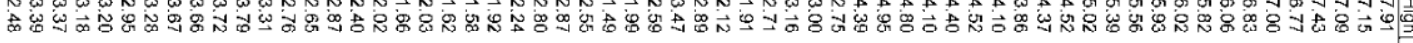

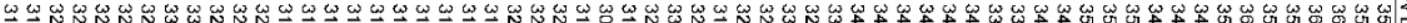

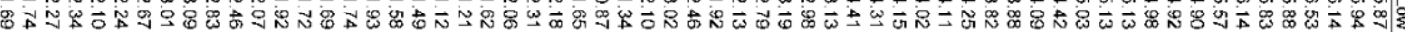

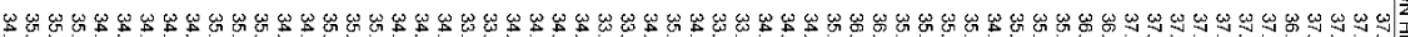

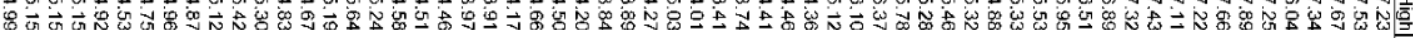

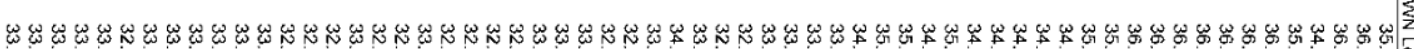

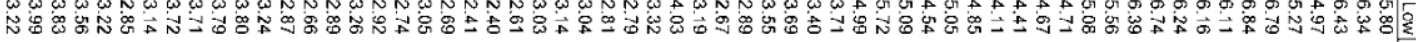

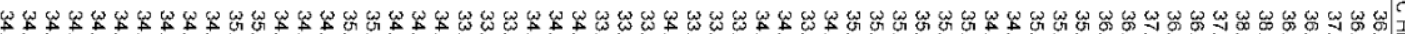

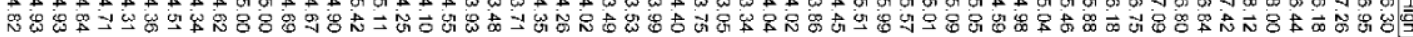

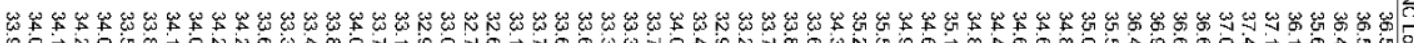

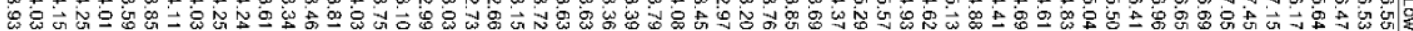

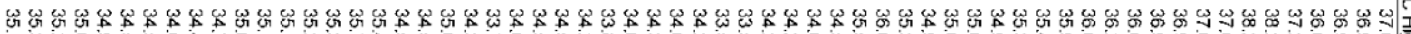

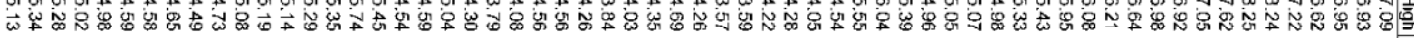

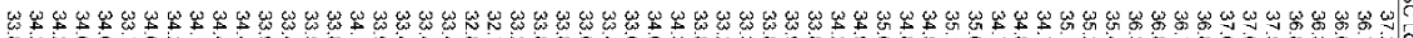

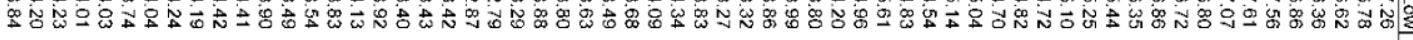

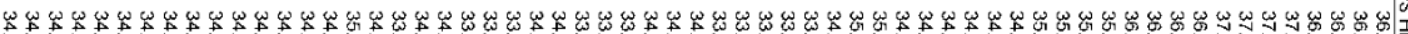

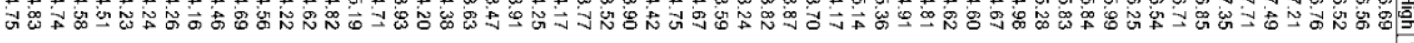

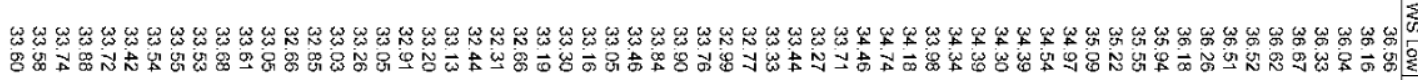

W

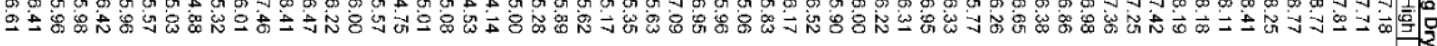

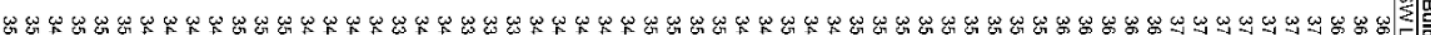

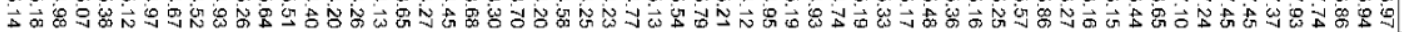

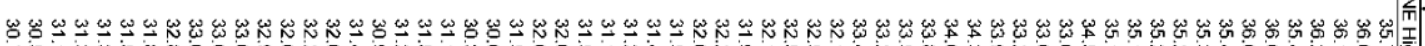

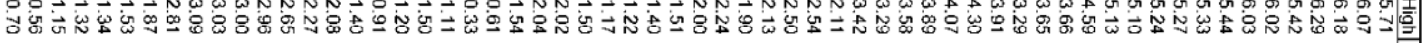

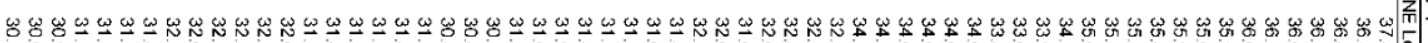

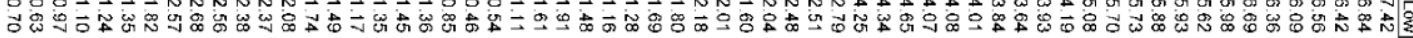

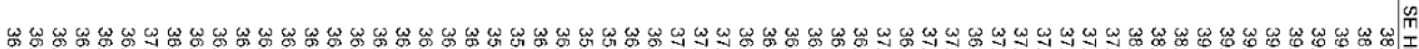

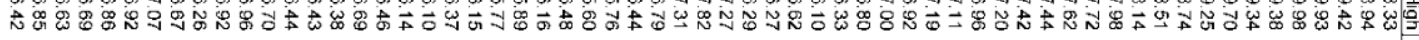
W

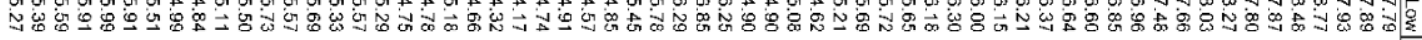

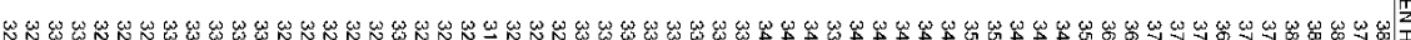

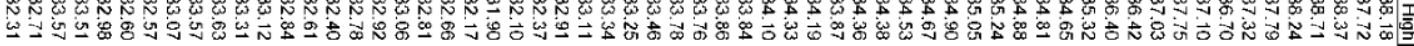

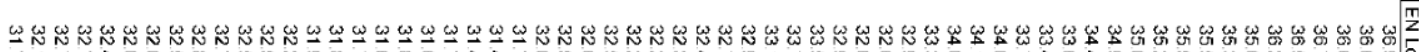
N $\vec{A}$ की

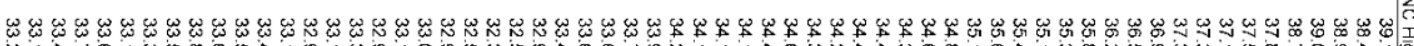

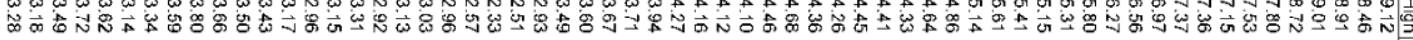

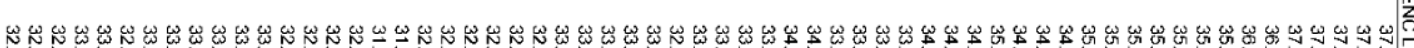

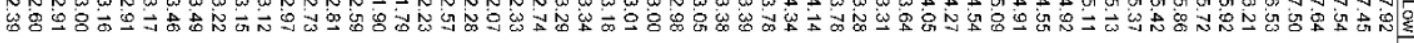

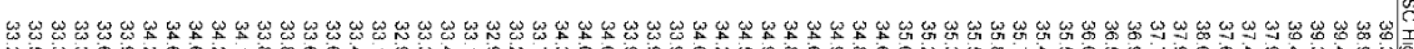

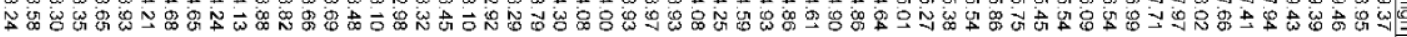

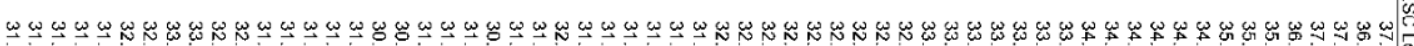

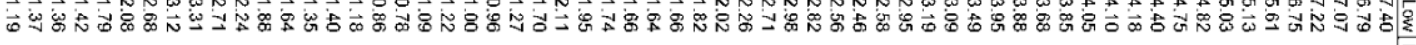

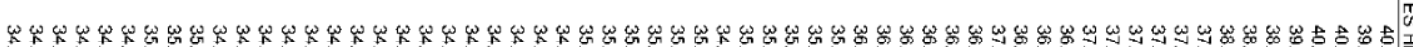

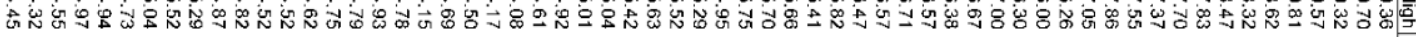

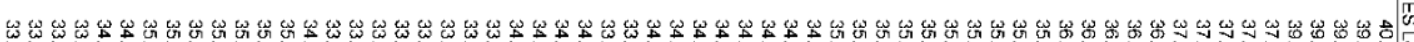

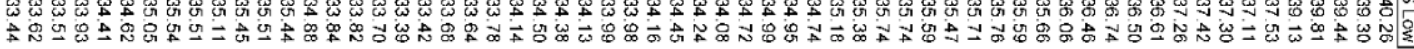




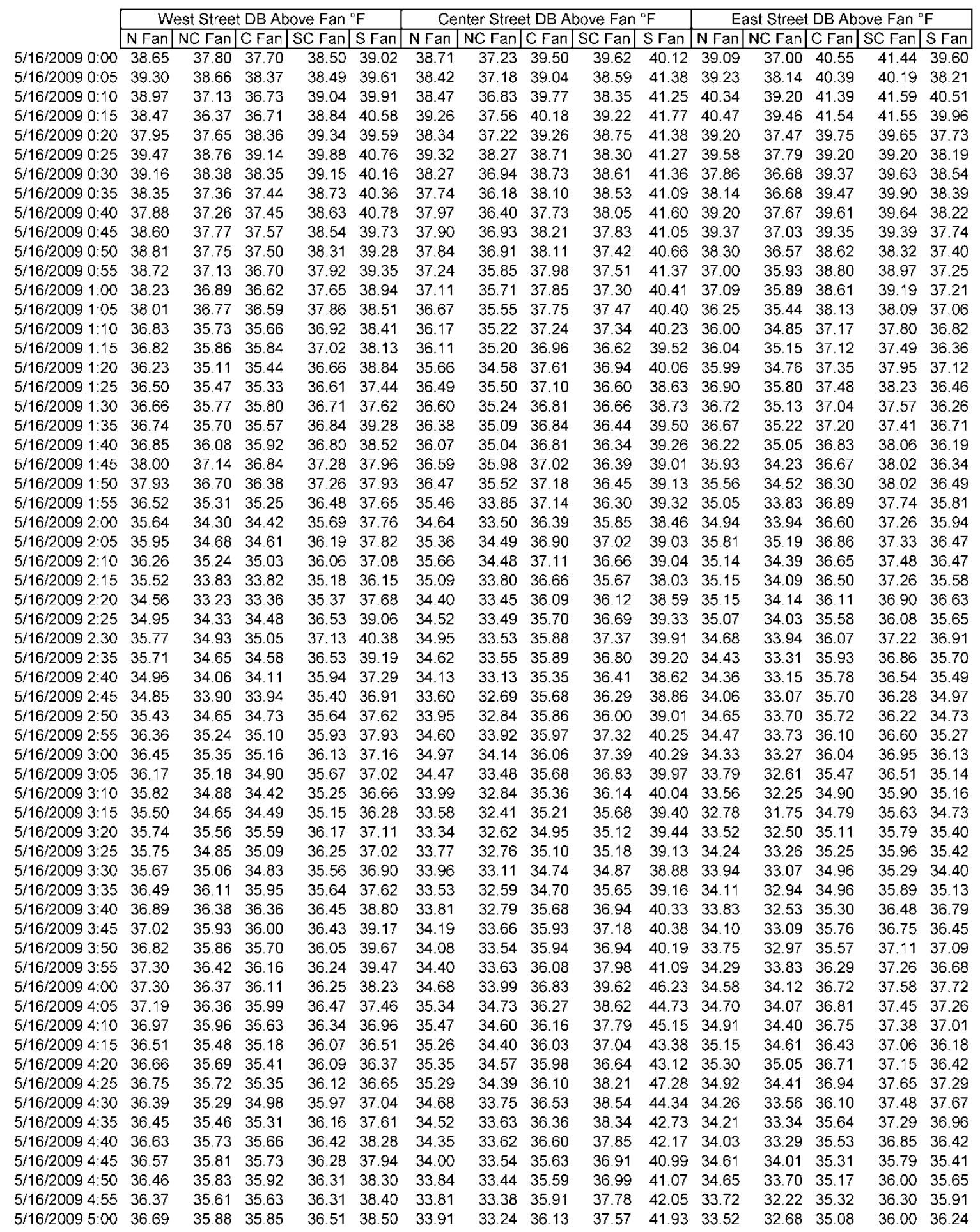




\begin{tabular}{|c|c|}
\hline \multicolumn{2}{|c|}{ Remote Wind Speed } \\
\hline & $\mathrm{MPH}$ \\
\hline $5 / 16 / 20090: 00$ & 1.1 \\
\hline $5 / 16 / 20090: 05$ & 1.6 \\
\hline $5 / 16 / 20090: 10$ & 0.4 \\
\hline $5 / 16 / 20090: 15$ & -0.1 \\
\hline $5 / 16 / 20090: 20$ & 0.0 \\
\hline $5 / 16 / 20090: 25$ & 0.1 \\
\hline $5 / 16 / 20090: 30$ & 2.3 \\
\hline $5 / 16 / 20090: 35$ & 2.8 \\
\hline $5 / 16 / 20090: 40$ & 1.8 \\
\hline $5 / 16 / 20090: 45$ & 1.2 \\
\hline $5 / 16 / 20090: 50$ & 1.7 \\
\hline $5 / 16 / 20090: 55$ & 4.3 \\
\hline $5 / 16 / 20091: 00$ & 4.0 \\
\hline $5 / 16 / 20091: 05$ & 4.0 \\
\hline $5 / 16 / 20091: 10$ & 3.5 \\
\hline $5 / 16 / 2009$ 1:15 & 2.7 \\
\hline $5 / 16 / 20091: 20$ & 4.3 \\
\hline $5 / 16 / 20091: 25$ & 2.5 \\
\hline $5 / 16 / 20091: 30$ & 0.4 \\
\hline $5 / 16 / 20091: 35$ & 0.0 \\
\hline $5 / 16 / 20091: 40$ & 1.6 \\
\hline $5 / 16 / 20091: 45$ & 1.6 \\
\hline $5 / 16 / 20091: 50$ & 1.7 \\
\hline $5 / 16 / 20091: 55$ & 2.2 \\
\hline $5 / 16 / 20092: 00$ & 4.1 \\
\hline $5 / 16 / 20092: 05$ & 8.5 \\
\hline $5 / 16 / 20092: 10$ & 4.2 \\
\hline $5 / 16 / 20092: 15$ & 5.0 \\
\hline $5 / 16 / 20092: 20$ & 2.9 \\
\hline $5 / 16 / 20092: 25$ & 1.3 \\
\hline $5 / 16 / 20092: 30$ & 2.3 \\
\hline $5 / 16 / 20092: 35$ & 3.7 \\
\hline $5 / 16 / 20092: 40$ & 3.4 \\
\hline $5 / 16 / 20092: 45$ & 3.6 \\
\hline $5 / 16 / 20092: 50$ & 4.1 \\
\hline $5 / 16 / 20092: 55$ & 5.3 \\
\hline $5 / 16 / 20093: 00$ & 5.3 \\
\hline $5 / 16 / 20093: 05$ & 4.4 \\
\hline $5 / 16 / 20093: 10$ & 5.1 \\
\hline $5 / 16 / 20093: 15$ & 4.1 \\
\hline $5 / 16 / 20093: 20$ & 1.8 \\
\hline $5 / 16 / 20093: 25$ & 0.8 \\
\hline $5 / 16 / 20093: 30$ & 2.5 \\
\hline $5 / 16 / 20093: 35$ & 2.3 \\
\hline $5 / 16 / 20093: 40$ & 2.0 \\
\hline $5 / 16 / 20093: 45$ & 2.4 \\
\hline $5 / 16 / 20093: 50$ & 2.8 \\
\hline $5 / 16 / 20093: 55$ & 4.2 \\
\hline $5 / 16 / 20094: 00$ & 6.2 \\
\hline $5 / 16 / 20094: 05$ & 5.2 \\
\hline $5 / 16 / 20094: 10$ & 4.9 \\
\hline $5 / 16 / 20094: 15$ & 4.6 \\
\hline $5 / 16 / 20094: 20$ & 4.4 \\
\hline $5 / 16 / 20094: 25$ & 4.2 \\
\hline $5 / 16 / 20094: 30$ & 3.0 \\
\hline $5 / 16 / 20094: 35$ & 2.3 \\
\hline $5 / 16 / 20094: 40$ & 1.0 \\
\hline $5 / 16 / 20094: 45$ & 1.4 \\
\hline $5 / 16 / 20094: 50$ & 1.0 \\
\hline $5 / 16 / 20094: 55$ & 1.2 \\
\hline $5 / 16 / 20095: 00$ & 1.8 \\
\hline
\end{tabular}

\begin{tabular}{|c|c|}
\hline \multicolumn{2}{|c|}{ Remote Wind Direction } \\
\hline $5 / 16 / 20090: 00$ & 107 \\
\hline $5 / 16 / 20090: 05$ & 109 \\
\hline $5 / 16 / 20090: 10$ & 110 \\
\hline $5 / 16 / 20090: 15$ & 110 \\
\hline $5 / 16 / 20090: 20$ & 110 \\
\hline $5 / 16 / 20090: 25$ & 110 \\
\hline $5 / 16 / 20090: 30$ & 112 \\
\hline $5 / 16 / 20090: 35$ & 163 \\
\hline $5 / 16 / 20090: 40$ & 181 \\
\hline $5 / 16 / 20090: 45$ & 182 \\
\hline $5 / 16 / 20090: 50$ & 185 \\
\hline $5 / 16 / 20090: 55$ & 216 \\
\hline $5 / 16 / 20091: 00$ & 218 \\
\hline $5 / 16 / 20091: 05$ & 223 \\
\hline $5 / 16 / 20091: 10$ & 231 \\
\hline $5 / 16 / 20091: 15$ & 231 \\
\hline $5 / 16 / 20091: 20$ & 230 \\
\hline $5 / 16 / 20091: 25$ & 229 \\
\hline $5 / 16 / 20091: 30$ & 228 \\
\hline $5 / 16 / 20091: 35$ & 228 \\
\hline $5 / 16 / 20091: 40$ & 228 \\
\hline $5 / 16 / 20091: 45$ & 228 \\
\hline $5 / 16 / 20091: 50$ & 228 \\
\hline $5 / 16 / 20091: 55$ & 228 \\
\hline $5 / 16 / 20092: 00$ & 226 \\
\hline $5 / 16 / 20092: 05$ & 196 \\
\hline $5 / 16 / 20092: 10$ & 219 \\
\hline $5 / 16 / 20092: 15$ & 214 \\
\hline $5 / 16 / 20092: 20$ & 200 \\
\hline $5 / 16 / 20092: 25$ & 196 \\
\hline $5 / 16 / 20092: 30$ & 198 \\
\hline $5 / 16 / 20092: 35$ & 207 \\
\hline $5 / 16 / 20092: 40$ & 217 \\
\hline $5 / 16 / 20092: 45$ & 210 \\
\hline $5 / 16 / 20092: 50$ & 196 \\
\hline $5 / 16 / 20092: 55$ & 216 \\
\hline $5 / 16 / 20093: 00$ & 218 \\
\hline $5 / 16 / 20093: 05$ & 230 \\
\hline $5 / 16 / 20093: 10$ & 227 \\
\hline $5 / 16 / 20093: 15$ & 215 \\
\hline $5 / 16 / 20093: 20$ & 215 \\
\hline $5 / 16 / 20093: 25$ & 215 \\
\hline $5 / 16 / 20093: 30$ & 212 \\
\hline $5 / 16 / 20093: 35$ & 196 \\
\hline $5 / 16 / 20093: 40$ & 195 \\
\hline $5 / 16 / 20093: 45$ & 195 \\
\hline $5 / 16 / 20093: 50$ & 212 \\
\hline $5 / 16 / 20093: 55$ & 218 \\
\hline $5 / 16 / 20094: 00$ & 208 \\
\hline $5 / 16 / 20094: 05$ & 209 \\
\hline $5 / 16 / 20094: 10$ & 207 \\
\hline $5 / 16 / 20094: 15$ & 214 \\
\hline $5 / 16 / 20094: 20$ & 211 \\
\hline $5 / 16 / 20094: 25$ & 220 \\
\hline $5 / 16 / 20094: 30$ & 242 \\
\hline $5 / 16 / 20094: 35$ & 238 \\
\hline $5 / 16 / 20094: 40$ & 237 \\
\hline $5 / 16 / 20094: 45$ & 211 \\
\hline $5 / 16 / 20094: 50$ & 210 \\
\hline $5 / 16 / 20094: 55$ & 210 \\
\hline $5 / 16 / 20095: 00$ & 210 \\
\hline
\end{tabular}

\begin{tabular}{|c|c|c|c|}
\hline & \multicolumn{3}{|c|}{ Remote Weather Readings } \\
\hline & Baro. ("Hg) & $\mathrm{DB}^{\circ} \mathrm{F}$ & $\mathrm{RH} \%$ \\
\hline $5 / 16 / 20090: 00$ & 25.81 & 36.86 & 82.9 \\
\hline $5 / 16 / 20090: 05$ & 25.81 & 37.36 & 84.3 \\
\hline $5 / 16 / 20090: 10$ & 25.82 & 38.18 & 84.7 \\
\hline $5 / 16 / 20090: 15$ & 25.82 & 38.67 & 84.8 \\
\hline $5 / 16 / 20090: 20$ & 25.82 & 38.11 & 85.1 \\
\hline $5 / 16 / 20090: 25$ & 25.82 & 38.03 & 85.8 \\
\hline $5 / 16 / 20090: 30$ & 25.82 & 37.15 & 87.1 \\
\hline $5 / 16 / 20090: 35$ & 25.82 & 36.54 & 87.3 \\
\hline $5 / 16 / 20090: 40$ & 25.83 & 36.61 & 87.3 \\
\hline $5 / 16 / 20090: 45$ & 25.83 & 36.02 & 87.1 \\
\hline $5 / 16 / 20090: 50$ & 25.83 & 35.88 & 87.8 \\
\hline $5 / 16 / 20090: 55$ & 25.83 & 35.35 & 88.2 \\
\hline $5 / 16 / 20091: 00$ & 25.83 & 35.02 & 88.8 \\
\hline $5 / 16 / 20091: 05$ & 25.84 & 34.74 & 89.5 \\
\hline $5 / 16 / 20091: 10$ & 25.83 & 34.57 & 89.7 \\
\hline $5 / 16 / 20091: 15$ & 25.83 & 34.56 & 90.7 \\
\hline $5 / 16 / 20091: 20$ & 25.84 & 34.26 & 91.3 \\
\hline $5 / 16 / 20091: 25$ & 25.84 & 34.29 & 91.7 \\
\hline $5 / 16 / 20091: 30$ & 25.84 & 34.58 & 91.6 \\
\hline $5 / 16 / 20091: 35$ & 25.84 & 34.75 & 91.9 \\
\hline $5 / 16 / 20091: 40$ & 25.84 & 34.80 & 92.1 \\
\hline $5 / 16 / 20091: 45$ & 25.84 & 35.40 & 93.1 \\
\hline $5 / 16 / 20091: 50$ & 25.84 & 34.81 & 93.2 \\
\hline $5 / 16 / 20091: 55$ & 25.84 & 35.09 & 93.7 \\
\hline $5 / 16 / 20092: 00$ & 25.84 & 33.68 & 92.9 \\
\hline $5 / 16 / 20092: 05$ & 25.84 & 32.73 & 91.8 \\
\hline $5 / 16 / 20092: 10$ & 25.85 & 33.42 & 93.1 \\
\hline $5 / 16 / 20092: 15$ & 25.85 & 32.43 & 91.6 \\
\hline $5 / 16 / 20092: 20$ & 25.84 & 32.77 & 93.0 \\
\hline $5 / 16 / 20092: 25$ & 25.84 & 33.31 & 93.5 \\
\hline $5 / 16 / 20092: 30$ & 25.85 & 33.32 & 93.4 \\
\hline $5 / 16 / 20092: 35$ & 25.85 & 33.19 & 93.1 \\
\hline $5 / 16 / 20092: 40$ & 25.85 & 33.11 & 92.8 \\
\hline $5 / 16 / 20092: 45$ & 25.85 & 32.88 & 92.8 \\
\hline $5 / 16 / 20092: 50$ & 25.85 & 32.85 & 93.1 \\
\hline $5 / 16 / 20092: 55$ & 25.85 & 32.61 & 93.2 \\
\hline 5/16/2009 3:00 & 25.85 & 32.60 & 93.7 \\
\hline 5/16/2009 3:05 & 25.85 & 32.09 & 93.1 \\
\hline $5 / 16 / 20093: 10$ & 25.84 & 31.88 & 93.3 \\
\hline $5 / 16 / 20093: 15$ & 25.85 & 31.74 & 93.9 \\
\hline $5 / 16 / 20093: 20$ & 25.85 & 31.99 & 94.4 \\
\hline $5 / 16 / 20093: 25$ & 25.85 & 32.19 & 94.5 \\
\hline $5 / 16 / 20093: 30$ & 25.85 & 32.64 & 95.5 \\
\hline $5 / 16 / 20093: 35$ & 25.85 & 33.19 & 96.1 \\
\hline $5 / 16 / 20093: 40$ & 25.85 & 33.37 & 95.8 \\
\hline $5 / 16 / 20093: 45$ & 25.85 & 33.13 & 95.2 \\
\hline $5 / 16 / 20093: 50$ & 25.85 & 32.45 & 94.1 \\
\hline $5 / 16 / 20093: 55$ & 25.85 & 32.20 & 94.4 \\
\hline $5 / 16 / 20094: 00$ & 25.85 & 32.61 & 95.6 \\
\hline $5 / 16 / 20094: 05$ & 25.85 & 32.60 & 95.1 \\
\hline $5 / 16 / 20094: 10$ & 25.85 & 32.95 & 94.8 \\
\hline $5 / 16 / 20094: 15$ & 25.85 & 33.15 & 93.9 \\
\hline $5 / 16 / 20094: 20$ & 25.85 & 32.96 & 92.6 \\
\hline $5 / 16 / 20094: 25$ & 25.84 & 32.88 & 92.2 \\
\hline $5 / 16 / 20094: 30$ & 25.84 & 33.19 & 92.6 \\
\hline $5 / 16 / 20094: 35$ & 25.84 & 33.48 & 93.3 \\
\hline $5 / 16 / 20094: 40$ & 25.84 & 33.38 & 93.4 \\
\hline $5 / 16 / 20094: 45$ & 25.84 & 33.59 & 93.9 \\
\hline $5 / 16 / 20094: 50$ & 25.84 & 33.58 & 93.5 \\
\hline $5 / 16 / 20094: 55$ & 25.84 & 33.61 & 94.0 \\
\hline $5 / 16 / 20095: 00$ & 25.85 & 33.36 & 94.3 \\
\hline
\end{tabular}




\begin{tabular}{|c|c|c|c|c|}
\hline & \multicolumn{4}{|c|}{ Tower Wind Speed (MPH) } \\
\hline & North & East & South & Wes \\
\hline $16 / 2009000$ & 4.6 & 4.1 & 2.9 & \\
\hline $16 / 20090: 05$ & & & 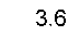 & \\
\hline 16/2009 0:10 & & 6 & & \\
\hline $16 / 20090: 15$ & & 6.3 & & \\
\hline $16 / 20090: 20$ & & . & 2 & \\
\hline $090: 25$ & & & & \\
\hline $090: 30$ & & 4.8 & 4 & . \\
\hline $0090: 35$ & & 4.2 & 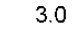 & . \\
\hline $090: 40$ & & 4.2 & 2 & . \\
\hline $090: 45$ & & 4. & & . \\
\hline $090: 50$ & & 3.2 & & s \\
\hline $90: 55$ & & 4.4 & 2 & 0.7 \\
\hline $091: 00$ & & 4.2 & 2 & 1 \\
\hline $0091: 05$ & & 4.3 & 5 & . \\
\hline $0091: 10$ & & 4 & 2 & 5.3 \\
\hline 009 1:15 & & 3.7 & 2 & 3.6 \\
\hline $0091: 20$ & & 4.0 & 2 & 5. \\
\hline $0091: 25$ & & 4.6 & 3 & $\begin{array}{l}4.8 \\
.8\end{array}$ \\
\hline $91: 30$ & & 4.3 & 1 & . \\
\hline $91: 35$ & & 3.5 & 2 & 5.3 \\
\hline $91: 40$ & & 3.7 & 2 & 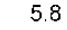 \\
\hline $91: 45$ & & 4 & 2 & . \\
\hline $91: 50$ & & 4.5 & 3 & i. \\
\hline $1: 55$ & & 4 & & . \\
\hline $2: 00$ & & 4 & 8 & . \\
\hline $2: 05$ & & & & . \\
\hline & & 4 & & 3. \\
\hline & & & & . \\
\hline & & & & . \\
\hline & & & & . \\
\hline & & & & i. \\
\hline & & & & . \\
\hline & & & & . \\
\hline & & & & . \\
\hline & & & & i. \\
\hline & & & & . \\
\hline & & & & . \\
\hline & & & & . \\
\hline & & & & . \\
\hline & & & & \\
\hline & & & 0 & \\
\hline & & & 9 & \\
\hline & & & .5 & \\
\hline & & & .5 & \\
\hline & & & & \\
\hline & & & & \\
\hline & & & & \\
\hline & & & & \\
\hline & & & & \\
\hline & & & & . \\
\hline & & & & 8.4 \\
\hline & & & 2 & \\
\hline & & 9 & 3 & \\
\hline 25 & & 1 & 3 & . \\
\hline 30 & & 6 & 9 & \\
\hline $4: 35$ & & 6 & 9 & \\
\hline $94: 40$ & & 0 & 3 & \\
\hline $94: 45$ & & 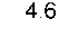 & 5 & \\
\hline & & & 3 & \\
\hline $4: 55$ & & 5.0 & 2.9 & 0.0 \\
\hline $5: 0$ & 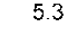 & 5.3 & 3.1 & \\
\hline
\end{tabular}

\begin{tabular}{|c|c|c|c|c|}
\hline & \multicolumn{4}{|c|}{ Tower Wind Direction } \\
\hline & \begin{tabular}{|l|l|} 
North \\
\end{tabular} & East & South & West \\
\hline $16 / 20090: 00$ & 21 & 68 & 339 & \\
\hline $16 / 20090: 05$ & 231 & 8 & & \\
\hline $16 / 20090: 10$ & 101 & 93 & & \\
\hline $16 / 20090: 15$ & 41 & 96 & & \\
\hline $1090: 20$ & 34 & 83 & 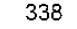 & 2 \\
\hline $990: 25$ & 2 & 7 & & \\
\hline $990: 30$ & 158 & 76 & $r$ & 2 \\
\hline $090: 35$ & 316 & 89 & $r$ & 2 \\
\hline 0.40 & 215 & 82 & & 2 \\
\hline $90: 45$ & 0 & 86 & & 2 \\
\hline $90: 50$ & 2 & 69 & 3 & 2 \\
\hline 0.55 & 303 & 50 & 3 & 2 \\
\hline $91: 00$ & 294 & 50 & 3 & 0 \\
\hline $91: 05$ & 284 & 68 & 3 & 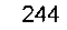 \\
\hline $91: 10$ & 321 & 35 & 3 & 2 \\
\hline $91: 15$ & 335 & 39 & 38 & 2 \\
\hline $91: 20$ & 314 & 56 & 336 & 2 \\
\hline $91: 25$ & 109 & 82 & 38 & 2 \\
\hline $91: 30$ & 14 & 82 & 37 & 2 \\
\hline $91: 35$ & 140 & 74 & 337 & $2+2>$ \\
\hline$: 40$ & 310 & 58 & 37 & 2 \\
\hline $1: 45$ & 30 & 56 & & 2 \\
\hline :50 & 95 & 69 & & 25 \\
\hline 55 & 36 & 86 & & 2 \\
\hline & 32 & 79 & & 2 \\
\hline & 55 & 78 & & 22 \\
\hline & 61 & 71 & & 2 \\
\hline & 66 & 8 & & 3 \\
\hline & & 77 & & 23 \\
\hline & & 44 & & 24 \\
\hline & & & & 0 \\
\hline & & 59 & & 1 \\
\hline & & & & 4 \\
\hline & & 9 & & 3 \\
\hline & & & & 23 \\
\hline & & & & 3 \\
\hline & & & & 4 \\
\hline & & & & 4 \\
\hline & & 80 & & \\
\hline & & & & \\
\hline & & 81 & & \\
\hline & & & & 5 \\
\hline & & & & \\
\hline & & & & \\
\hline & & & & 23 \\
\hline & & & & 23 \\
\hline & & & & 23 \\
\hline & & & & 23 \\
\hline & & & & 23 \\
\hline & & & & 23 \\
\hline & & & & 2 \\
\hline & & & & 24 \\
\hline & 14 & 103 & 37 & 4 \\
\hline$: 25$ & 45 & 70 & 37 & 24 \\
\hline 30 & & 0 & 6 & 24 \\
\hline $4: 35$ & 49 & 77 & 37 & - \\
\hline $4: 40$ & & & 38 & 23 \\
\hline & & & 38 & 24 \\
\hline & & 81 & & \\
\hline - & 292 & 79 & 338 & 24 \\
\hline $160000-500$ & 37 & 75 & 338 & \\
\hline
\end{tabular}

\begin{tabular}{|c|c|c|c|}
\hline & \multicolumn{3}{|c|}{ Steam Duct Discharge Temp } \\
\hline & 1 & 2 & 3 \\
\hline $5 / 16 / 20090: 00$ & 118.40 & 117.93 & 118.0 \\
\hline $5 / 16 / 20090: 05$ & 118.85 & 118.40 & 18.5 \\
\hline $16 / 20090: 10$ & 8.71 & 118.26 & 18.3 \\
\hline $5 / 16 / 20090: 15$ & 119.47 & 119.05 & 19.1 \\
\hline $16 / 20090: 20$ & 118.52 & 118.06 & 118.19 \\
\hline $16 / 2009025$ & 19.08 & 118.65 & 118.73 \\
\hline $16 / 20090: 30$ & 18.91 & 118.48 & 118.56 \\
\hline $16 / 20090: 35$ & 118.46 & 118.01 & 118.13 \\
\hline $16 / 2009040$ & 118.70 & 118.24 & 118.36 \\
\hline $16 / 20090: 45$ & 119.03 & 118.59 & 118.69 \\
\hline $16 / 20090: 50$ & 118.91 & 118.46 & 118.57 \\
\hline $16 / 20090: 55$ & 119.30 & 118.85 & 118.95 \\
\hline 16/2009 1:00 & 119.03 & 118.58 & 118.68 \\
\hline 16/2009 1:05 & 118.75 & 118.28 & 118.40 \\
\hline $16 / 20091: 10$ & 118.35 & 117.87 & 118.01 \\
\hline 16/2009 1:15 & 119.19 & 118.74 & 118.84 \\
\hline $16 / 20091: 20$ & 118.51 & 118.05 & 118.18 \\
\hline $16 / 20091: 25$ & 119.28 & 118.82 & 118.93 \\
\hline $16 / 20091: 30$ & 119.06 & 118.62 & 118.71 \\
\hline $16 / 20091: 35$ & 118.60 & 118.14 & 118.26 \\
\hline $16 / 20091: 40$ & 118.74 & 118.27 & 18.39 \\
\hline $16 / 20091: 45$ & 119.93 & 119.50 & 19.57 \\
\hline $16 / 20091: 50$ & 120.31 & 119.88 & 119.94 \\
\hline $16 / 20091: 55$ & 119.87 & 119.45 & 119.52 \\
\hline $16 / 20092: 00$ & 118.77 & 118.30 & 118.42 \\
\hline $2: 05$ & 120.11 & 119.70 & 119.75 \\
\hline $2: 10$ & 18.77 & 118.33 & 118.41 \\
\hline$: 15$ & 18.72 & 118.27 & 118.37 \\
\hline 20 & 5 & 119.00 & 119.08 \\
\hline 25 & 6 & 119.96 & 120.00 \\
\hline 30 & & 119.62 & 119.67 \\
\hline 35 & 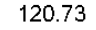 & 120.34 & 120.37 \\
\hline 40 & & 120.24 & 20.28 \\
\hline 45 & & 119 & 19.39 \\
\hline & & 120 & 20.18 \\
\hline & & 20.41 & 20.44 \\
\hline & & 20.46 & 50 \\
\hline & & 3 & 79 \\
\hline & & 19.82 & 90 \\
\hline & & 119. & 82 \\
\hline 20 & & 0 & 80 \\
\hline & & 4 & 46 \\
\hline & & 4 & 08 \\
\hline & & 5 & 8.87 \\
\hline & & 1 & 19 \\
\hline & & 1 & \\
\hline & & 5 & 20.13 \\
\hline & & 42 & 120.49 \\
\hline & & 120 & 120.39 \\
\hline & & 119. & 119.60 \\
\hline & & 30 & 118.72 \\
\hline & & & 118.09 \\
\hline & & 18.63 & 118.75 \\
\hline $5 /$ & & 119.33 & 119.42 \\
\hline & & 8.17 & 18.31 \\
\hline $4: 35$ & 5 & 118.57 & 118.70 \\
\hline $5 / 1$ & 49 & 118.00 & 118.17 \\
\hline 45 & 8 & 118.18 & 110.0 \\
\hline 150 & 86 & 118.37 & 118.5 \\
\hline $4: 55$ & 9.09 & 118.60 & 118.7 \\
\hline $5 / 16 / 20095: 00$ & 119.13 & 118.64 & 118.77 \\
\hline
\end{tabular}




\section{$\underline{\text { Technical Benefit - Response Model }}$}

A power plant customer would consider using this ACC technology based on the benefit in mitigating wind impact on the turbine backpressure for their particular plant equipment. As an example, a Western U. S. Power Plant that reviewed the technology could benefit as follows.

The plant turbine curve had the generic shape shown in Figure 20. Benefits could come from Backpressure Improvements for their turbine, which would depend on their maximum backpressure allowable and where that utility operates on the turbine curve, or Fan Speed reduction to support a given load, resulting in a lower plant parasitic load. Benefits might be Lower fuel consumption and/or increase power production for that plant.

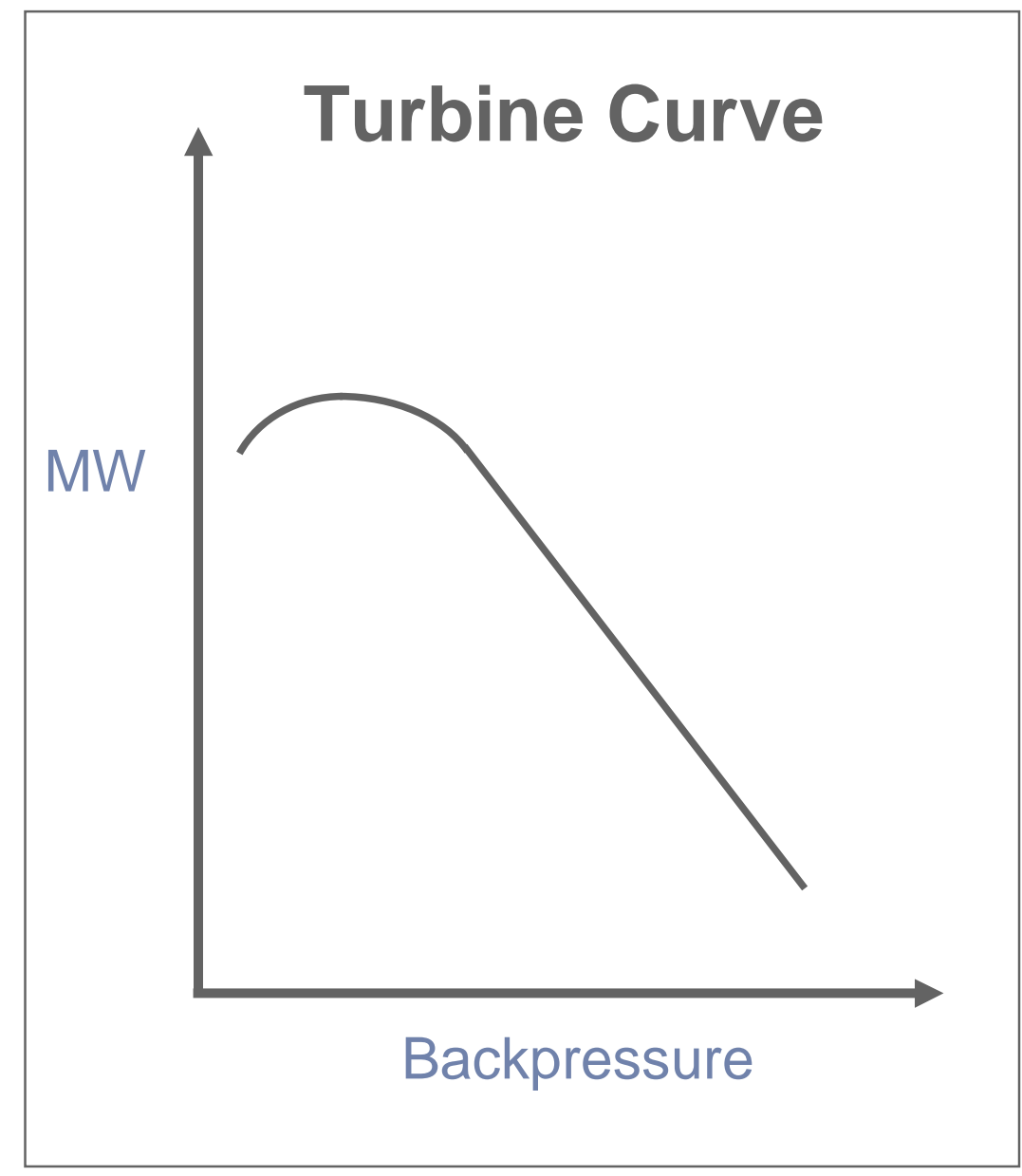

Figure 20: Generic Turbine Curve 
Example Plant Issue at this plant:

- 25-30MW derate for approximately 1 week over the summer (anecdotal)

- Wind causes backpressure spikes toward 8.5" turbine limit, of 1.5".

- Operators over compensate by decreasing plant load contributing to the plant derate problem.

- Operational Comments, from plant personel:

At high temperatures, they want to run as close as safely possible to 8.5 " turbine limit, because they can maintain MW output by using more fuel. Otherwise, they would have to lower the backpressure via less fuel, which means less MW production.

- Because of wind gusts, they routinely have to operate 1.5" below 8.5 " than they normally would like because of the potential for wind gusts to cut the $500 \mathrm{MW}$ turbine if it goes over $8.5^{\prime \prime}$. This is a 9MW problem.

This solution currently looks to improve the plant by $1 \mathrm{MW}$

$\square$ They currently don't know how they would measure an improvement without a lot of measuring devices which may not be cost effective.

$\square$ They are looking for a solution that would improve heat exchange by $5 \%$

- Financial Comments

This is a public utility and fuel costs are passed on in their rates.

$\square$ Capital expenditures can be put into the rate base with the agreement of the State PUC.

- The profit of the company is based on their investment and capacity. They are looking for a capital requests only and directly related to improving capacity.

- Efficiency only manifests itself in terms of fuel savings and since fuel savings are passed through, there is limited interest or need for efficiency gain. Capacity is critical, reduction in de-rate is important.

$\square$ They want to invest in a solution. They require a business case based on capacity gains with investment to get PUC approval to the capital approval.

- Solving the de-rate can happen from either pushing more air (Guide Vanes, Fan Power, etc) or Heat Exchange Surface (more modules). They are willing to work with SPX to understand the economics of different options.

- An IPP might consider an annual performance based price, but they as a public utility will not. 


\section{Commercial Conclusion:}

Public Utilities do not make the best customers, as SPX has not been able to provide a proven solution to satisfy this Utilities need.

\section{Current Commercial Plans / Actions:}

- New ACC's

- Improvement to SPX product rating, based on wind modeling evaluations in this project can save costs and improve Plant efficiencies

- Use of wind guides can help further improve costs for new products especially at high wind standards

- Retrofit ACC's

- Talk with US ACC customers with IPP status to understand potential in private sector (About 2/3rd of US market is IPP vs. public)

- Evaluate US launch vs. opportunistic retrofit selling

\section{Relevance and Outcomes/Impacts}

Thermoelectric generation is water intensive. Each kilowatt-hour (kWh) generated requires an average of 25 gallons of water. Increased attention is being paid to the availability of adequate water supplies required to produce electricity, and to the potential impact of energy operations on water quality. The goal of this DOE funding is to minimize the freshwater withdrawal and consumption in coal-based thermoelectric power plant.

Within three cooling technologies used in power plants today, dry cooling system has negligible water withdrawal and consumption. However, high capital cost makes dry systems unfavorable comparing to wet cooling towers. Developing technologies that improve performance and reduce costs of dry cooling towers is critical to manufacturers and plants looking to reduce water usage.

\section{Conclusions}

1. The improvement of ACC thermal performance after SPX wind guide installation was real and substantial. The benefit increases when wind speed increases. Testing of the improvement indicates there is a $5 \%$ improvement in heat transfer coefficient at high wind and $1 \%$ improvement at low wind speed.

2. The magnitude of the improvement is not currently verifiable to customer satisfaction, as being greater than the cost of adding the Wind Guide modification to the tower. Cost improvement of the modification is needed. Our early experience with customers indicates substantial skepticism in accepting test results, as projected for specific sites by CFD modeling. Customers are requesting a guarantee of results, in spite of the verification testing completed for this project. This illustrates the ultra-conservative nature of the utility customer base in applying new technology. 
3. SPX continues to look for ways to reduce cost of this improvement and ways to incorporate the results into new ACC design to yield the improved efficiency benefit demonstrated in this test program.

4. SPX design engineering concepts for new ACC installations include wind mitigation considerations using the wind control effect additions to some ACC's.

SPX is very grateful to the DOE NETL and Black Hills Power for the opportunity to conduct this test and verify the improvement predicted by the CFD model.

\section{$\underline{\text { References }}$}

1. United States Geological Survey in year 2000.

http://pubs.usgs.gov/circ/2004/circ1268/

2. DOE/NETL Water \& Power Plant Overview Meeting - June 2006.

http://www.netl.doe.gov/technologies/coalpower/ewr/pubs/WaterMeeting2006.pdf

3. "INNOVATIVE APPROACHES AND TECHNOLOGIES FOR IMPROVED POWER

PLANT WATER MANAGEMENT" NETL Program Facts, Jan. 2005

4. Maulbetsch, $J$ and DiFilippo, M, The effects of Wind on the Performance of Air-cooled Condensers, CTI Journal, 2007, Vol. 28, No.2, PP18-26

5. Schrey, Hans-Georg, et al, Method and device for directing flow in air-cooled condenser systems, Published Patent Application Number 20050006050, January 13, 2005

6. Yang, Jidong, et al, Air Guide for Air Cooled Condenser, Patent Application Serial Number 11/966,777; Filed on December 28, 2007 (not published).

7. http://www.netl.doe.gov/technologies/coalpower/ewr/pubs/Water_Energy_Brochure.pdf 


\section{Appendix Material:}

\section{Statement of Project Objectives (SOPO)}

\section{Improved Performance of an Air Cooled Condenser (ACC) Using SPX Wind Guide Technology at Coal-Based Thermoelectric Power Plants}

\section{A. OBJECTIVES}

The water savings potential of Dry Cooling technology in Power Generation, when one compares application to evaporative cooling processes, is enormous. The drawbacks have always included efficiency variation, efficiency reduction of power plants, and capital and operating costs of the ACC units. Cooling water savings for the total U.S. could be 7.8 Billion Gallons/Day, if all power and industrial towers were outfitted with Dry Cooling technology. By this standard the savings would be 940 Million Gallons/Day in California alone, enough water for 13 Million residents domestic usage. [Domestic usage is inside the house, 71 GPD/person, source: AWWA]. This magnitude of water savings would allow relief from drought conditions or additional growth in many water-starved portions of the continental United States.

This project is aimed at reducing the efficiency variation of ACC cooling in common wind conditions, defined as $10-30 \mathrm{mph}$ at the power plant site. SPX Cooling is developing physical enhancements to the base ACC unit to improve fan airflow in these windy conditions. Application of the Wind Guide Technology to an existing ACC is simply a method of enhancing air entry to the ACC reducing normal power plant $A C C$ efficiency loss at these wind conditions.

CFD Modeling of possible solutions has been undertaken by SPX Cooling Technologies prior to this proposal. A pilot-scale test is required to resolve application and optimization issues and effectiveness of an airflow enhancing solution for the specifics of the validation plant. In essence, does the computer simulated technology work for a specific full-scale ACC cooling unit?

The project will add a CFD optimized new technology to an existing ACC cooling process at a selected coal-fired power plant, providing for and then quantifying the plant efficiency improvement for the main plant condenser cooling process. Performance and operating parameters of the technology in application will be determined. The project will compare this technology's capability to data generated on the existing system.

\section{B. SCOPE OF WORK}

A utility industry partner will be selected. Particular plant parameters will be modeled to determine an optimized Wind Guide solution for that plant. That 
power plant ACC will be outfitted with Wind Guide technology to create an operational application of the technology in plant dry cooling. Testing will determine the benefits of such a use for this technology.

\section{TASKS TO BE PERFORMED}

Task 1: Identify and partner with a utility company that has an existing Air Cooled Condenser of the appropriate size to install and measure the effect of wind guide addition to their ACC.

Task 2: Model the existing ACC, as installed, recording the relevant physical parameters considering at no wind and summer prevailing wind conditions. Modify the model by adding wind guides. The ACC model, with and without wind guide technology, will be completed using CFD. Finally, calculate predicted fan airflow gains at target conditions.

Task 3: Monitor the existing plant performance by determining the ACC performance and associated turbine output. The following plant data is to be measured/monitored, exhaust steam pressure, exhaust steam temperature, condensate flow rate, wind speed, wind direction, atmospheric pressure, and ambient dry-bulb temperature. Site and fan condition measurements may include ACC inlet air dry-bulb temperature, ACC outlet air dry-bulb temperature, fan horsepower, and fan pressure.

Task 4: Retrofit the ACC adding Wind Guide technology. In steps SPX CT Engineering will design the wind guide installation, construct, re-place testing/monitoring instruments, and commission the new process configuration.

Task 5: Monitor the ACC performance with wind guide technology and validate CFD modeling. Correlations between turbine pressure and wind speed, fan airflow and wind speed, ACC inlet temperature and wind speed with the wind guide technology in place will to be analyzed. Results will be compared with the data obtained from the ACC test without wind guides.

\section{DELIVERABLES}

Task 6: Project Reports/Presentations will be provided. SPX CT will create quarterly technical progress reports during the project execution and a final scientific/technical report at the completion of the project. Technical verbal reports may be provided, as required, to detail the progress of the project towards the intended goals.

\section{Technical basis and feasibility of SPX wind quide technology}

SPX Cooling Technologies (SPX CT) has spent several years conducting research on wind guide technologies for ACC. All the studies use computational fluid 
dynamics (CFD), a computer-based methodology for the solution of the fundamental equations (Navier-Stokes equations) of fluid flow, to model the wind effect on ACC fan performance. CFD lets you investigate airflow patterns, i.e., wakes and recirculation zones, heat transfer, pressure drop, etc. This analysis is performed by sub-dividing the region to be modeled into a large number of small cells and iteratively solving fundamental equations. CFD has a good track record for modeling a large number of applications.

Guide vane technology was developed for wet cooling towers using CFD and cooling tower field test results showed good agreement with model prediction. CFD has been a successful research and development tool for SPX CT.

SPX CT has two pending patent applications on the wind guide technology for ACC $[5,6]$

\section{Anticipated public benefits of wind guide technology for ACC}

Thermoelectric generation is water intensive, whether it is derived from fossil fuels such as coal, oil, and natural gas, or from nuclear power. In fact, each kilowatt-hour $(\mathrm{kWh})$ generated requires an average of 25 gallons of water. This means that U.S. citizens may indirectly depend on water to turn on lights and run appliances as much as they may directly use water to take showers and water their lawns ${ }^{[7]}$. As the nation's growing economy drives the need for more electricity, demands on the use of water for power generation also will grow. The direct and indirect demand for water for energy production will increasingly compete with demands from other sectors of the economy. As a result, increased attention is being paid to the availability of adequate water supplies required to produce electricity, and to the potential impact of energy operations on water quality.

Due to their negligible water withdrawal and consumption, dry cooling towers were mainly used in areas with restricted water resources in the past. High capital cost made them unfavorable comparing to wet cooling towers. Take a typical $300 \mathrm{MW}$ coal-fire power plant as an example, a wet cooling tower recirculates 140,000 GPM of water at a cooling range of $20^{\circ} \mathrm{F}$. The water consumption due to evaporation is about 3 million gallons per day. The capital cost is approximately 4 million dollars. By using an ACC, water consumption is negligible. However, its capital cost is roughly 40 million dollars, ten times higher than the wet cooling tower.

After 1990, the factors driving the use of dry cooled power plants have drastically changed. The world market for dry cooling has multiplied by about 20 times in the last 13 years. Some of the reasons that considered in today's selection of dry cooling systems are:

- Environmental regulations for water saving. 
- Environmental regulations, limiting the temperature, increase in rivers and seaside.

- Local regulations favoring equipment without a plume discharge.

- Flexibility in the selection of the power plant site.

- Life expectancy exceeding power plant life with reduced maintenance, no use of water treatment chemicals and no need for fire protection system.

- Shorter lead-time for power plant permits.

As the use of ACCs becomes more popular, cost reduction and adequate cooling performance under wind are more critical to the ACC manufacturers. SPX wind guide technology can boost the ACC performance by $7 \%$ at no wind condition. It also helps reducing the wind effect by $10 \%$ under 20 miles/hour quartering wind. This performance gain has a direct impact on the efficiency of a coal-fired power plant. It lowers the turbine backpressure and increases the power plant output. Economic impact of SPX wind guide technology is tremendous.

\section{Technical Approach and Understanding}

The main goal of the proposed project is to validate the benefits of wind guide technology in an ACC at coal-fired electric power plants. The project will detail the ramifications of joining this new technology with an existing ACC in coal-fired power plants. The project will quantify the performance gain of the ACC after implemented with the technology.

Performance of the wind guide technology will be determined by monitoring the steam temperature and pressure, condensate flow rate for the plant. Fan pressure and horsepower, and inlet/outlet air dry-bulb temperatures may be examined before and after the wind guide installation. Measurement will be checked with CFD model predictions, as possible. 


\subsection{Tasks Plan prior to project execution}

\subsubsection{Identify and partner with a utility company that has an existing ACC}

1.1.1.1 Identify up to 3 utility companies that has an existing ACC. A preferred existing ACC is a middle size, less than 30 modules (fan cells) unit. Preferably the ACC is located in a windy region without many obstacles around the ACC.

1.1.1.2 Partner with one utility company.

Negotiate with identified utility companies and partner with the company that provides the best opportunity to test and get conclusive data.

\subsubsection{Model the ACC with and without wind guide technology using CFD}

\section{SPX CT claims priority to the CFD models that predict performance of an $\mathrm{ACC}$.}

1.1.2.1 Model the existing ACC using CFD

Set up a CFD model to simulate the performance of the existing ACC. Two conditions, no wind and summer prevailing wind condition, need to be modeled. Calculate fan performance at each condition.

1.1.2.2 Model the ACC with wind guide technology

Modify the model by adding wind guides. Multiple cases need to be studied with a calculated fan performance in each case.

- Modify the model using wind guide configuration \#1. Run the model at no wind condition. Calculate the fan performance.

- Re-run the configuration \#1 model at the summer prevailing wind condition. Calculate the fan performance.

- Modify the model using wind guide configuration \#2. Run the model at no wind condition. Calculate the fan performance.

- Re-run the configuration \#2 model at the summer prevailing wind condition. Calculate the fan performance.

\subsubsection{Monitor the existing ACC performance}

\subsubsection{Install testing/monitoring instruments}

In order to determine the ACC performance and associated turbine output, the following plant data need to be measured/monitored. These measurements will serve as the basis for measuring the modification improvement on the ACC.

- Exhaust steam pressure (turbine back pressure) 
- Exhaust steam temperature (for comparison)

- Condensate flow rate

- Wind speed and direction

- Atmospheric pressure

- Ambient dry-bulb temperature

- ACC inlet air dry-bulb temperature

Fan performance and site condition measurements may include [possibly useful in further gauging the ACC improvement] This step may be modeled at SPX Cooling Technology Development Center to assess its usefulness in ACC evaluation:

- ACC outlet air dry-bulb temperature

- Fan motor horsepower

- Fan total pressure at fan inlet

A large number of dry bulb temperature probes are required to measure ACC inlet air temperatures.

Typical fan total pressures can be measured using Kiel probes. It typically requires 8 Kiel probes along eight quadrants of a fan. ACC inlet and outlet temperatures can also be determined. [Number of fans to be determined]

Wind speed should be measured above the upper edge of the ACC. Care should be taken that the measurement is not spoiled by other factors such as the air mass flow, buildings, etc.

\subsubsection{Data collection}

Testing is preferred during windy months. Continuous monitoring may last for a number of months.

\subsubsection{Analyze test data}

Correlations between turbine backpressure and wind speed, fan CFM and wind speed, ACC inlet temperature and wind speed should be analyzed.

\subsubsection{Validate CFD model}

Data collected from the field test will be compared to the model prediction for tested conditions. For given wind speed and direction, the CFD model predicts fan CFM for each fan cell. Measured fan CFM or the total CFM of the unit will be compared with CFD calculation, as possible. Adjustment can be made to the CFD model in order to align with test results. 


\subsubsection{Retrofit the ACC using wind guide technology}

\subsubsection{Engineering design / drafting}

SPX CT Engineering will review and inspect the existing ACC structure to determine its ability to accept added weight, structural loads, and physical changes that would result from the wind guide construction on the particular chosen site. SPX CT Engineering will design the required structure for the guide vanes. A bill of materials [BOM] for the modifications will be prepared.

1.1.4.2 Remove testing/monitoring instruments

Some of the testing/monitoring instruments installed in the previous test may need to be removed before guide vane installation.

\subsubsection{Construction and installation}

SPX CT Construction will receive materials and prepare the site for retrofit construction work of the existing tower. Guide vanes will be installed in stages. A series of tests will be conducted at each stage.

\subsubsection{Monitor the ACC performance with wind guide technology and validate CFD modeling}

1.1.5.1 Install testing/monitoring instruments Refer to task 5.1.3.1, same number of instruments need to be installed.

1.1.5.2 Data collection with wind guide configuration \#1 installed In order to determine the fan performance, test will be conducted for a period of time with wind guide configuration \#1 installed.

\subsubsection{Analyze test data}

Correlations between turbine backpressure and wind speed, fan CFM and wind speed, ACC inlet temperature and wind speed need to be analyzed. Compare the results with the correlation obtained from the ACC test without wind guides.

\subsubsection{Validate CFD model}

Data collected from the field test will be compared to the model prediction for tested conditions. For given wind speed and direction, the CFD model predicts fan CFM for each fan cell. Measured fan CFM or the CFM of the unit will be compared with CFD calculation.

1.1.5.5 Data collection with wind guide configuration \#2 installed Conduct the test for a period of time after the wind guide configuration \#2 is installed. 


\subsubsection{Analyze test data}

Correlations between turbine backpressure and wind speed, fan CFM and wind speed, ACC inlet temperature and wind speed need to be analyzed. Compare the results with the correlation obtained from the ACC test without wind guides.

\subsubsection{Validate CFD model}

Data collected from the field test will be compared to the model prediction for tested conditions. For given wind speed and direction, the CFD model predicts fan CFM for each fan cell. Measured fan CFM or the CFM of the unit will be compared with CFD calculation.

\subsubsection{Project reports/presentations}

\subsubsection{Project reports}

SPX CT will provide informal quarterly technical progress reports during the project execution and a final scientific/technical report at the completion of the project.

\subsubsection{Technical Briefings}

SPX CT can provide informal semi-annual technical progress presentations during the project execution and a final scientific/technical presentation at the completion of the project at the discretion of the DOE project manager. These presentations could be given at the DOE project manager's office, at the SPX CT Offices or Development Center, or via teleconference at the discretion of the DOE project manager. 


\section{Text from Relevant Quarterly Reports:}

\section{Tasks Being Executed During the Period, 7/1/10-9/30/10:}

Data analysis has been pursued during the period. It has been determined that the data collected is sufficient to show the advantage provided by the Wind Guide technology.

The plan is to finish analysis for the collected data from the validation site and proceed to reporting.

\section{Tasks Executed During the Previous Period, 1/1/10-3/31/10:}

The most important testing period occurs during warm weather at the ACC site. The plan is to gear-up with more complete instrumentation for the summer 2010 period at the validation site.

\section{Tasks Previously Completed, Period, 10/1/09-12/31/09:}

Task 3: Analysis of the existing plant performance by determining the ACC performance and associated turbine output. The following plant data is used for this analysis: exhaust steam pressure, exhaust steam temperature, condensate flow rate, wind speed, wind direction, atmospheric pressure, and ambient drybulb temperature. Site condition measurements include ACC inlet air dry-bulb temperature, fan horsepower, and fan pressure.

Task 5: Analysis of ACC performance with wind guide technology and validation of the CFD modeling. The following plant data is used for this analysis: correlations between turbine pressure, output, and wind speed, fan airflow and wind speed, ACC inlet temperature and wind speed with the wind guide technology in place will to be analyzed. Results are being compared with the data obtained from the ACC test without wind guides.

The charts below are an example of the results from the analysis process in progress during the period. These results will be detailed further in upcoming reporting. The charts detail an improvement in the heat transfer coefficient for the ACC with the Wind guide technology in place. 

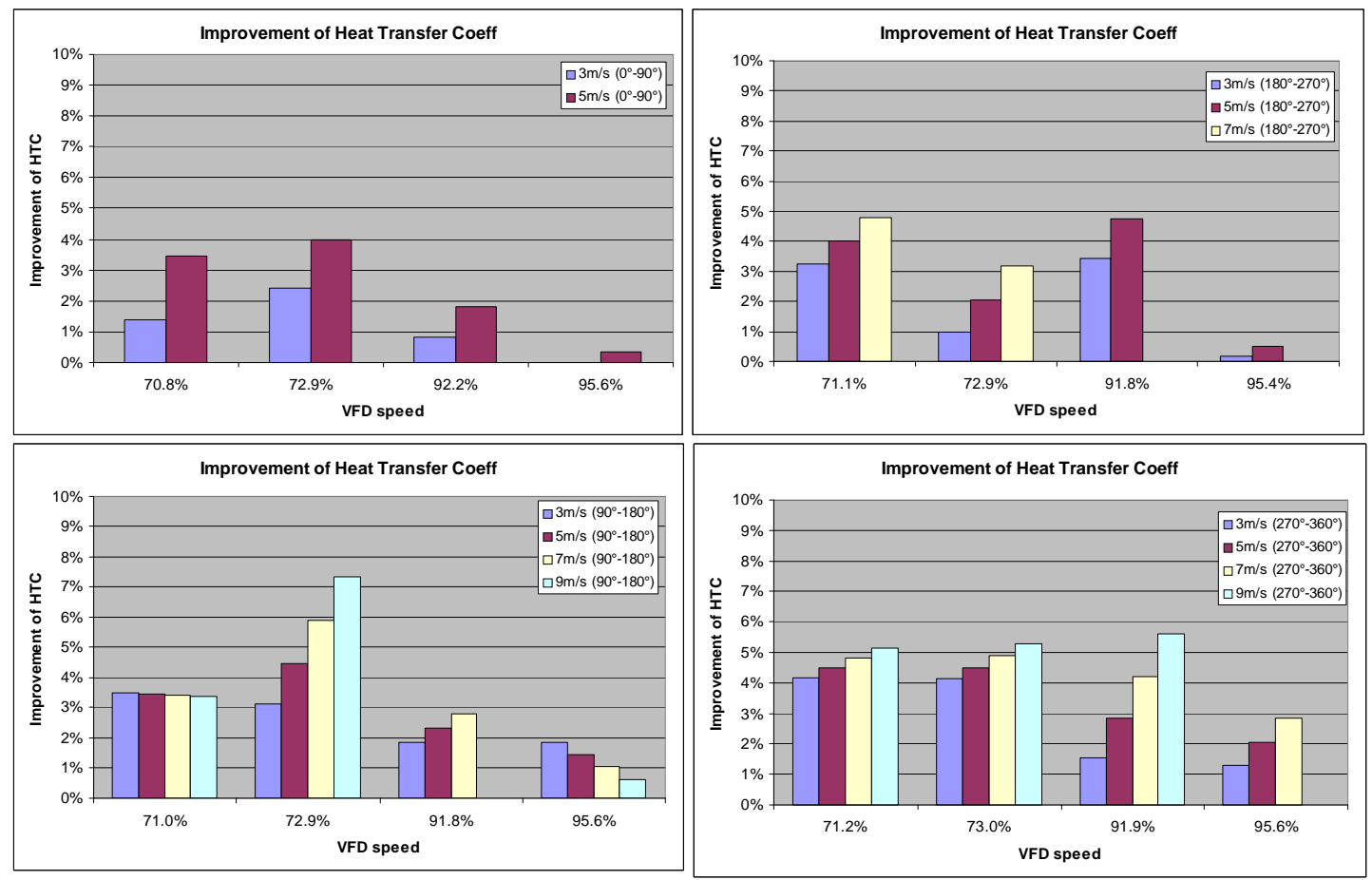

Plan to Complete the Project: Complete the objective of the project determining the benefits using ACC Wind Guide technology in ACC applications, based on the data from Tasks 3 and 5.

Task 6: Report results.

\section{Tasks Completed, Period, 7/1/09-9/30/09:}

Task 3: Continued monitor the existing plant performance by determining the ACC performance and associated turbine output. The following plant data is being measured/monitored, exhaust steam pressure, exhaust steam temperature, condensate flow rate, wind speed, wind direction, atmospheric pressure, and ambient dry-bulb temperature. Site condition measurements include ACC inlet air dry-bulb temperature, ACC outlet air dry-bulb temperature, fan horsepower, and fan pressure.

Task 4: Retrofit the ACC adding Wind Guide technology. In steps SPX CT installed, constructed, executed the modifications in the field, re-positioned testing/monitoring instruments, and commission the new process configuration. 


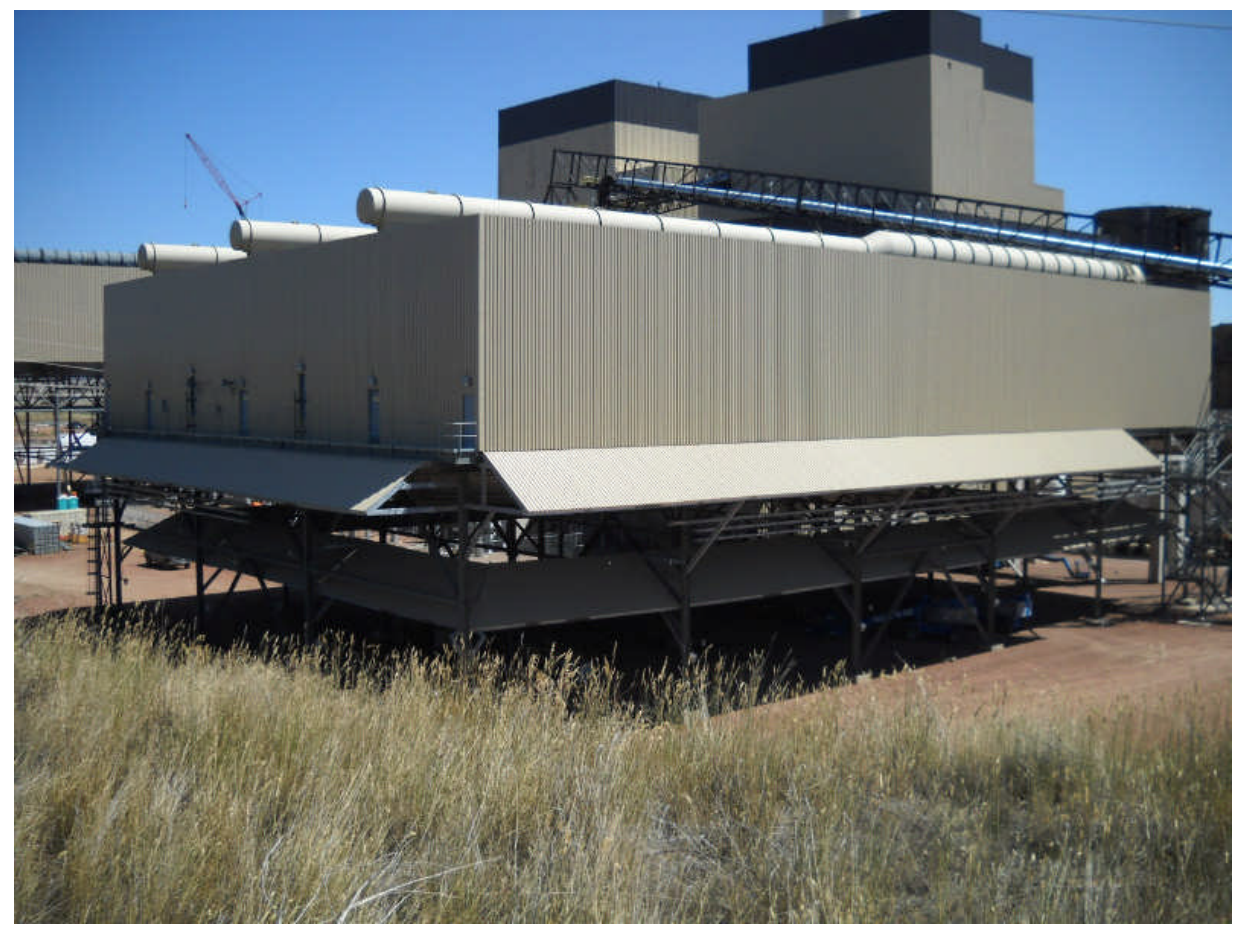

Tasks Completed, 4/1/09-6/30/09:

Task 2 - Model Existing ACC - CFD modeling of the site has been completed and the model will be used to compare the base condition to the modified ACC.

Task 3 - Monitor Existing ACC - Instrumentation installed on the existing ACC has been used to complete baseline data including airflows, temperatures, plant operating parameters, and site weather data.

Task 4 - Install Modification - The work to modify the ACC has proceeded with completion of the engineering, creation of fabrication, shop, and installation drawings, manufacturing system entry, procurement of materials, and preassembly fabrication. Site tasks completed, based on this modification design include creation of the Labor Bid Package and the erector bid meeting. Work on the project is proceeding well and is ahead of schedule.

\section{Tasks Completed, 1/1/09-3/31/09:}

Task 1: Identify and partner with a utility company that has an existing Air Cooled Condenser of the appropriate size to install and measure the effect of wind guide addition to their ACC. This project has completed the contracting and planning stage. SPX Cooling Technologies has visited the host facility to discuss the concept and optimize the fit of this test at the power facility. This optimized SPX Wind Guide system has been proposed and accepted by the customer/host. The Host Agreement has been completed and signed by the Host Plant/Company and SPX Cooling Technologies. The project moves to the instrumentation, baseline testing, design, modification installation, operation, and testing. 